CIRJE-F-1020

\title{
The Impact of Auction Choice on Revenue in Treasury Bill Auctions - An Empirical Evaluation
}

\author{
Daniel Marszalec \\ The University of Tokyo
}

August 2016

CIRJE Discussion Papers can be downloaded without charge from:

http://www.cirje.e.u-tokyo.ac.jp/research/03research02dp.html

Discussion Papers are a series of manuscripts in their draft form. They are not intended for circulation or distribution except as indicated by the author. For that reason Discussion Papers may not be reproduced or distributed without the written consent of the author. 


\title{
The Impact of Auction Choice on Revenue in Treasury Bill Auctions - An Empirical Evaluation
}

\author{
Daniel Marszalec ${ }^{\mathrm{a}, 1}$ \\ ${ }^{a}$ Graduate School of Economics, University of Tokyo 7-3-1 Hongo, Bunkyo-ku, Tokyo 113-0033, Japan
}

\begin{abstract}
I evaluate whether uniform price or discriminatory auctions are revenue-superior for selling Treasury bills. To this end, I apply two structural econometric models, Hortacsu and McAdams (2010) and Fevrier, Preget and Visser (2002), to a dataset on Polish zerocoupon bonds. My secondary aim is to analyze mutual inconsistencies in prediction from these models. I find that both agree on the revenue-superiority of discriminatory auctions, by between $0.01 \%$ and $1.5 \%$; the models' predictions are contradictory in only $7 \%$ of auctions. The large-scale agreement of two vastly different models gives confidence that the conclusions are data-driven, and not a modeling artifact.
\end{abstract}

JEL Classification: D44, C57, G23

Keywords: Auctions, Treasury Bills, Divisible Goods, Structural Estimation

Most OECD countries sell their debt through auctions of treasury bills and bonds. In 2015 -16 the UK alone issued over $£ 120$ bn worth of gilts this way. ${ }^{2}$ Picking the appropriate auction mechanism, even if only giving a small percentage revenue gain, may thus give an issuing government significant reductions in debt servicing costs.

Economic theory in its current state, however, does not provide a definite answer as to which auction format is revenue-optimal for the sale of divisible goods such as shares, bonds or treasury bills. Even when the scope of comparison is restricted to two of the most popular mechanisms - discriminatory and uniform price auctions - the outcome is inconclusive. Recent work of Ausubel, Cramton, Pycia, Rostek and Weretka (2014) shows that either rule can revenue-dominate, depending on characteristics of the individual

\footnotetext{
Email address: dmarszalec@e.u-tokyo.ac.jp (Daniel Marszalec)
}

${ }^{1}$ I would like to thank Paul Klemperer, Steve Bond, Ian Jewitt and Thees Spreckelsen for their comments and advice. Financial support from the ESRC, RES and the British Academy is also gratefully acknowledged.

${ }^{2}$ Data from UK Debt Management Office's website, http://www.dmo.gov.uk/index.aspx?page=Gilts/Net_Issuance_Data . Queried in August 2016. 
demand functions. This theoretical ambiguity is mirrored by observing actual auction mechanism choices across the world: the survey by Brenner, Galai and Sade (2006) covers 48 countries, 24 of which use discriminatory price, 9 use uniform price, and a further 9 use both. Such variation suggests that the superiority of one auction format over another is an empirical matter, and results may be country-specific. Though there are a number of structural econometric models analyzing the performance of discriminatory and uniform auctions, ${ }^{3}$ each has been run on a separate dataset. Hence, the degree to which results are driven by the model choice, rather than the data, has remained an open question.

I use a dataset on Polish treasury bill auctions for 52-week and 2-year maturities to compare two structural econometric models directly. The models I analyze are Hortacsu and McAdams (2010) (HMA henceforth), originally run on Turkish data, and Fevrier, Preget and Visser (2002) (FPV henceforth), which was first run on French data. These two models differ both in terms of the economic assumptions that underlie them, as well as the econometric methods that are used in their estimation.

The two main aims of this paper are to, firstly, analyze the Polish dataset using two aforementioned models to determine which auction type is revenue superior, and secondly, to evaluate the mutual consistency of the results that these two models generate. Given the diverging theoretical and methodological assumptions, if the conclusions from both models are in agreement, that would provide an intuitively compelling reason for believing that the conclusions are data-driven, and not just modeling artifacts.

My results suggest that the discriminatory auction setup, prevailing during the period of my data, performs no worse than a uniform price system. I find that this auction is revenue-superior on both of the securities in my dataset. The HMA model predicts revenue difference of approximately $0.01 \%$ on the 52 week bills, and up to $0.66 \%$ on the 2 year bonds in favor of the discriminatory auctions. Predictions from the FPV model are in the same direction, but are considerably larger, proposing a revenue difference of $0.11 \%$ on 52 week bills, and up to $1.5 \%$ on 2 year bonds.

At the level of individual auctions, both models predict the same direction of revenuedominance in over $80 \%$ of cases, and only contradict each other in $7 \%$ of the data. In the remaining cases, at least one model cannot find a significant revenue-difference. Since the broad conclusions from both models are in agreement, it is plausible that the conclusions are data-sensitive, and not driven by modeling assumptions.

In Section $1 \mathrm{I}$ discuss the main differences between the discriminatory and uniform price auction rules, and in Section 2 I present a generalization of Wilson's (1979) share auction model, and solve it out under the two differing sets of assumptions, corresponding

${ }^{3}$ For example Hortacsu (2002) and Hortacsu and McAdams (2010) for Turkey, Fevrier et al. (2002) and Armantier and Sbai (2006) for France, Kastl (2011) for Czech Republic and Kim and Ryu (2006) and Kang and Puller (2008) for South Korea. 
to the two models I analyze. Section 3 describes the institutional setting of the Polish market for treasury bills, and discusses the auction participants. In section 4, I describe how to apply the HMA model to the data, and present the results from estimation. Section 5, in turn, discusses the estimation of FPV model, and presents its results. Comparison of the results from the two models with each other, and past literature, are is carried out in section 6 . Section 7 concludes.

\section{Description of the Discriminatory and Uniform Pricing Rules}

Discriminatory and uniform price auctions are pricing and allocation rules for the sale of multiple homogenous items. Usually, the total amount of goods for sale is fixed, but this amount is infinitely divisible. In this context, a bid submitted by an auction participant is a function, mapping from quantities to prices, or vice versa. In most practical applications of either pricing rule, the auctioneer pre-specifies a grid over the set of prices and quantities. For example, the minimum increment on quantity could be 100 bonds, and the degree of precision for specifying a price could be $\$ 0.01$ to $\$ 100$ of face-value. Bidders then submit price-quantity pairs, rather than continuous demand functions, specifying what amount of the good they are willing to buy, and at what price.

After receiving all the participants' bids the auctioneer orders the individual bids in decreasing price order, and picks a cut-off price - frequently called the 'stop-out price' that equates the bidders' demand with the aggregate supply. Prices paid by the winning bidders, on the quantities won, will differ across the two rules. In the uniform price auction all winning bidders pay the stop-out price on all units won. In the discriminatory auction, each accepted bid is paid at full face value, so different bidders pay different prices. A graphical representation of the pricing difference is shown in Figure 1.

Figure 1: Payments under uniform-price and discriminatory rules

(a) Uniform-price

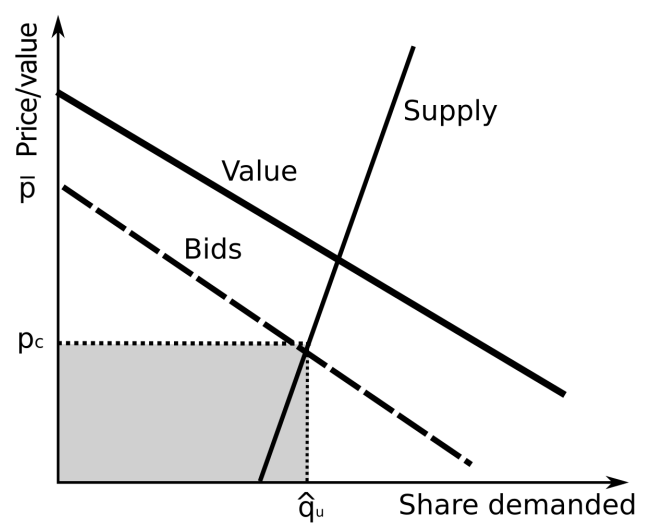

(b) Discriminatory

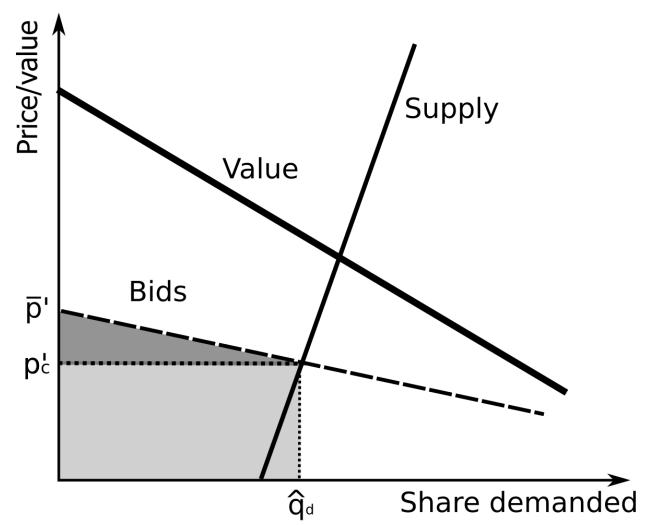

From the auctioneer's point of view, the total revenue from a uniform price auction is depicted by the shaded rectangle in Figure 1a: this is the total quantity $\hat{q}_{u}$ multiplied 
by the stop-out price $p_{c}$. In the discriminatory auction, Figure $1 \mathrm{~b}$, the revenue equals the $\hat{q}_{d} \cdot p_{c}^{\prime}$ rectangle, plus the shaded triangular area, which depicts the additional revenue, above the stop-out price, on all inframarginal accepted bids.

With similarly shaped demand curves, revenue from the discriminatory price auction appears higher. However, bidding incentives differ across the two auctions, and it is unlikely that bidders would submit the same demands under both rules. In the uniform price auction, the incentives for shading (i.e. bidding below value) are low; only the marginal winning bid is paid 'at full price', and all inframarginal accepted bids are paid at a price lower than bid. In the discriminatory auction, since each accepted bid is paid in full, the bidders need to shade carefully at each portion of their demand curve: winning bids submitted at a price close to the bidder's true valuation will earn little profit. Thus incentives for shading are stronger in discriminatory auctions, and bidders are likely to submit flatter demand curves. Consequently the stop-out prices will usually be lower in the discriminatory auction, as reflected by Figure 1 , where $p_{c}^{\prime}<p_{c}$. The relevant comparison is then between the stop-out price under the uniform price rule, and the 'average weighted price' under discriminatory pricing. The result of this comparison is not intuitively obvious.

\section{Economic Theory on Share Auctions}

Both econometric models analyzed in this paper are based on the auction-theoretic model of Wilson (1979). Assume there are $n \geq 2$ risk-neutral bidders participating in a discriminatory auction for a known aggregate quantity of $\mathrm{Q}$ treasury bills. Each bidder $i$ observes a private signal, $s_{i}$, and has a (marginal) valuation function of the form $v\left(q, s_{i}, s_{-i}\right)$, where $q$ denotes the quantity, and $s_{-i}=\left[s_{1}, . ., s_{i-1}, s_{i+1}, \ldots, s_{n}\right]$ is the vector of signals of $i^{\prime} s$ rivals. A bidder does not observe the signals of his rivals, but I assume that he knows the distribution they are drawn from, as well as $n$, the total number of bidders. At this stage of the model no further assumptions of symmetry, nor any specific parametric dependence between the bidders' signals, are necessary.

Each bidder's strategy is a function of the price, $p$, and the bidder's individual signal, $s_{i}$; I denote this bidding function by $y_{i}\left(p, s_{i}\right)$. To solve the model, the strategies are restricted to be differentiable, strictly decreasing functions. The market-clearing price ('stop-out price') $p^{c}$ is defined as the price where:

$$
\sum_{j=1}^{n} y_{j}\left(p^{c}, s_{j}\right)=Q \quad \text { or equivalently : } \quad q_{i}\left(p^{c}, s_{i}\right)=Q-\sum_{j \neq i} y_{j}\left(p^{c}, s_{j}\right)
$$

The first equation states that at $p^{c}$, aggregate demand equals aggregate supply. The second equation re-states this situation from bidder $i^{\prime} s$ perspective: for him, the stop-out price equates his individual demand function, with his residual supply. Since each bidder only observes his own signal, the stop out price is random from their viewpoint. However, 
as each bidder knows the distribution of others' signals, they can infer the equilibrium distribution of the stop-out price, conditional on their own information and submitted demand. This distribution is defined as:

$$
H\left(p \mid y_{i}(p)\right)=\operatorname{Pr}\left(p^{c} \leq p\right)=\operatorname{Pr}\left(y_{i}(p) \leq Q-\sum_{j \neq i} y_{j}\left(p^{c}\right)\right) .
$$

Each bidder is then faced with an optimization problem: to pick a demand function $y_{i}(p)$ that maximizes the expected surplus at every $p$, conditional on the bidder's own signal and (if applicable) the other bidders' signals that can be inferred at that price. The optimization problem is:

$$
\max _{y_{i}(p)} \int_{0}^{\infty}\left(\int_{0}^{y_{i}(p)} E_{s_{-i} \mid p, s_{i}}\left(v\left(q, s_{i}, s_{-i}\right)-y_{i}^{-1}\left(q, s_{i}\right)\right) d q\right) d H\left(p, y_{i}(p)\right) .
$$

This optimization program can then be solved by using calculus of variations to obtain an Euler equation for estimation or other analysis. To complete the model and apply it to data, we will need to specify a parametrization for the valuation function, and a means of recovering the $\mathrm{H}$-distribution from the data. The latter step is particularly complicated, since the H-distribution itself depends on optimal bidding strategies, and usually will not have a closed-form characterization.

\subsection{The Hortacsu and McAdams (2010) model - private values}

The main intuition of the HMA model is best captured in a simpler setting, presented by Hortacsu (2002). The model makes the assumption of symmetric bidders, pure private values, and identically and independently distributed signals. Under these assumptions, $v_{i}\left(q, s_{i}, s_{-i}\right)=v\left(q, s_{i}\right)$. Each bidder's valuation now depends on his own signal only, and every bidder's signals are drawn from the same distribution. The optimization program in (2) then becomes:

$$
\max _{y_{i}(p)} \int_{0}^{\infty}\left(\int_{0}^{y_{i}(p)}\left(v\left(q, s_{i}\right)-y_{i}^{-1}\left(q, s_{i}\right)\right) d q\right) d H\left(p, y_{i}(p)\right)
$$

Solving this program gives an Euler equation of the form:

$$
v\left(y_{i}(p), s_{i}\right)=p+\frac{H\left(p, y_{i}\left(p, s_{i}\right)\right)}{\frac{\partial}{\partial p} H\left(p, y_{i}\left(p, s_{i}\right)\right)} .
$$

This equation implicitly defines the optimal bidding function, and the set of all bidders' functions constitute a Bayesian Nash equilibrium of the auction game. The expression suggests at each point where $\mathrm{H}$ is strictly positive (i.e. at any price above the lower bound of the support), the bidder will under-report his true valuation, shading it by 
$\frac{H\left(p, y_{i}\left(p, s_{i}\right)\right)}{\frac{\partial}{\partial p} H\left(p, y_{i}\left(p, s_{i}\right)\right)}$. Deriving an equivalent optimality condition for discrete value and bid functions is more involved, and is one of the major contributions of Hortacsu and McAdams (2010). Their method relies on finding a lower $(\underline{v})$ and upper $(\bar{v})$ bound for each step in the value function, rather than a point estimate. ${ }^{4}$ Supposing that the value function has $K$ steps, for each step $k$ this gives a pair of value estimates, such that $v_{k} \in\left[\underline{v}_{k}, \bar{v}_{k}\right]$. The equations used to derive $\underline{v}$ and $\bar{v}$ also depend on the H-distribution as well as on the step-size in the price/quantity grid. In the limit when the step-size collapses to zero, the influence of discreteness diminishes, and both of the bounds collapse to equation (4).

\subsection{The Fevrier, Preget and Visser (2002) model - common values}

In line with Wilson's (1979) original model, FPV assume pure common values. This means that the true value of treasury bills is exactly the same to all bidders, so that $v_{i}\left(q, s_{i}, s_{-i}\right)=V$, for all $\mathrm{i}$. The common value has a distribution function $F_{V}(w)=$ $\operatorname{Pr}(V \leq w)$. All bidders are assumed to be symmetric, and each of them receives an independent signal, the distribution of which depends on the realization of $V$; this conditional distribution is denoted by $F_{S \mid V}(s \mid w)=\operatorname{Pr}\left(S_{i} \leq s \mid V \leq w\right)$. From these assumptions, signals are IID conditional on the true realization of $V$. The realization of each bidder's signal is private information, and not observed by his rivals or the seller, but the two distributions, $F_{V}$ and $F_{S \mid V}$ are common knowledge.

Under these assumptions, and using $\bar{p}$ to denote the largest price such that $y\left(p, s_{i}\right) \geq$ 0 , the objective function can be rewritten as:

$$
\max _{y_{i}\left(p, s_{i}\right)} \int_{0}^{\infty}\left(\int_{0}^{y_{i}(p)} E_{s_{-i} \mid p, s_{i}, V}\left((V-p) y_{i}\left(p, s_{i}\right)-\int_{p}^{\bar{p}} y_{i}\left(u, s_{i}\right) d u\right) d q\right) d H\left(p, y_{i}(p), V\right) \text {. }
$$

Note that the expectations operator and the H-density now both condition on $\mathrm{V}$; this is relevant because the individual signals, $s_{i}$, have a distribution which depends on $\mathrm{V}$. Using this to find the Euler condition, gives:

$$
E_{s_{-i} \mid p, s_{i}, V}\left((V-p) \frac{\partial H\left(p, y_{i}(p, s), V\right)}{\partial p}-H\left(p, y_{i}(p), V\right)\right)=0
$$

with the H-density and its derivative evaluated at $y=y_{i}\left(p, s_{i}\right)$. Since $H$ is nonnegative, and $\frac{\partial H}{\partial p}>0$ this equation, analogously to equation (4), suggests that the bidder participating in a discriminatory auction will again shade his bid. ${ }^{5}$ To facilitate estima-

\footnotetext{
${ }^{4} \mathrm{~A}$ more detailed explanation of the HMA model is provided in Appendix A.

${ }^{5}$ Appendix D in Fevrier et al. (2004) discusses the identification properties of this model.
} 
tion the Euler-equation can also be re-written as:

$$
E_{s_{i}, s_{j}}\left\{(n-1)\left[E_{V \mid S}\left(V \mid S_{i}=s_{i}, S_{j}=s_{j}\right)-p\right] * 1_{p^{c} \leq p}-E_{p^{c}}\left[\left(p-p^{c}\right) 1_{p^{c} \leq p}\right]\right\}=0 .
$$

In the above equation $1_{p^{c} \leq p}$ is the indicator function, taking the value of 1 when $p^{c} \leq p$, and zero otherwise. This eliminates the need to calculate the H-density, but instead a means of estimating $E(V \mid \ldots)$ from the data is needed.

\section{Description of the Polish Treasury Bill Auction System}

My dataset contains information from Polish auctions for 52-week treasury bills (52wTB for short) and 2-year bonds (2yB henceforth). It covers the period May 2004 to June 2007 for 52wTB, and September 2003 to June 2007 for 2yB. The Polish Ministry of Finance supplied both the raw auction data, and the secondary-market yields for both securities. During the time period covered by my data, the Polish economy was experiencing a period of steady growth, with little financial instability.

Both of the securities I analyze are zero-coupon "pure discount" bonds. The 52wTB is, according to the Ministry of Finance, their most important short-term security, and primarily used for liquidity management. However, an additional function of the 52wTB is to provide the basis for calculating the annual coupons on longer-term (10- and 15-year) variable-coupon bonds. The Ministry auctioned off on average 1 bnPLN (roughly $\$ 306 \mathrm{~m}$ ) of these bills weekly. According to a Ministry representative, the two-year zero-coupon bonds were in the past primarily used to balance the average duration of government debt, but have declined in significance over time. Two-year bonds were auctioned monthly, with roughly 2.3 bnPLN $(\$ 707 \mathrm{~m})$ sold on average, per auction. ${ }^{6}$

Bonds and treasury bills have been sold via discriminatory auction in Poland since 1991, with the institutional design drawing heavily on the French system. Participation is only open to primary dealers, though these institutions have an obligation to forward bids from other investors. To obtain a primary dealer status, a bidding institution (e.g. bank or brokerage house) must apply for a license from the Ministry of Finance, and meet a number of viability criteria with regard to payment terms. Once the license has been granted, the dealers must satisfy various activity rules to be eligible for a license renewal. However, these requirements are not stringent. In my dataset, I observe 19 different primary dealers, not all present throughout the whole sample.

Bidders express their demands within the auction by submitting price-quantity pairs; each bidder may submit as many pairs as they want. Each 52-week bill has face-value of 10,000 PLN, while the two-year bonds have a value of 1,000 PLN each; to maintain consistency, my dataset has re-scaled all of the 'face prices' to 100. The minimum quantity

\footnotetext{
${ }^{6}$ The approximate exchange rate during the period covered by my sample was 3.27 PLN to $\$ 1$.
} 
Table 1: Auction summary statistics, by security type

\begin{tabular}{lll}
\hline & 52 week bills & 2 year bonds \\
\hline Cover ratio & $2.7(1.0)$ & $2.7(1.0)$ \\
Submitted bids & $103.6(26.4)$ & $144.5(36.8)$ \\
Satisfied bids & $46.8(24.1)$ & $59.1(26.1)$ \\
Bidders & $12.3(1.0)$ & $12.8(1.8)$ \\
Winners & $7.6(2.2)$ & $8.8(2.0)$ \\
Bids per bidder & $8.4(2.2)$ & $11.5(3.1)$ \\
Maturity (days) & $364.0(\mathrm{~N} / \mathrm{A})$ & $785.5(50.4)$ \\
Supply (mPLN) & $828.2(246.7)$ & $2155.7(655.8)$ \\
\hline Means reported (standard deviations in brackets).
\end{tabular}

for each bid is 100.000 PLN, and if a bidder wishes to participate in a given auction, his total demand must exceed $1 \mathrm{mPLN}$, which is usually less than $1 \%$ of aggregate supply.

The supply of securities at each auction is announced in advance, though the Ministry of Finance is permitted to withdraw some of the securities if demand is lacking; in practice this occurs very rarely. ${ }^{7}$ In addition, the Ministry may organize a top-up auction, shortly after the main auction has finished. The legal framework permits the Ministry to offer extra $20 \%$ of base-auction supply in the top-up auction, at the weighted average price obtained in the main auction. ${ }^{8,9}$ The Ministry has never used this opportunity on the 52 -week bills, while roughly $40 \%$ of the 2-year bond auctions are followed by a top-up phase. The econometric models considered in this paper do not take into account the existence of top-up auctions. ${ }^{10}$

The period spanned by my data covers 103 of $52 \mathrm{wTB}$, and 42 of $2 \mathrm{yB}$ auctions. The dataset records all the price-quantity pairs actually submitted by the bidders at the auction, as well as the stop-out price. Table 1 shows that auctions for both maturities are well covered, with demand exceeding supply more than twofold; it unsurprising that the Ministry has not needed to use its power of supply-restriction.

Roughly $45 \%$ of submitted bids are accepted (fully or in part) in the $52 \mathrm{wTB}$ auctions,

\footnotetext{
${ }^{7}$ In my data, all 52-week auctions sell exactly the announced supply, and over 95 percent of 2-year bond auctions sell precisely the announced amount. The ratio of sold-to-announced bonds varied much more in the mid- and late 1990s, when the financial system in Poland was more volatile.

${ }^{8}$ The allocation of supply in the top-up auction is based on the proportions allocated to each bidder in the main auction.

${ }^{9}$ The Polish top-up auctions are analogous to ONC2-type 'non-competitive' bids, discussed in Fevrier et al. (2002).

${ }^{10}$ As of yet, there are no theoretical models I am aware of which would explicitly model the effect of top-up auctions.
} 
Table 2: Bidder statistics (calculated for $52 \mathrm{wTB} \mid 2 \mathrm{yB}$ )

\begin{tabular}{|c|c|c|c|c|c|c|c|c|}
\hline \multirow{2}{*}{$\begin{array}{c}\text { Name } \\
1\end{array}$} & \multicolumn{2}{|c|}{ Active in } & \multicolumn{2}{|c|}{ Total Bids } & \multicolumn{2}{|c|}{$\begin{array}{l}\text { Avg.Demand } \\
\text { (mPLN) }\end{array}$} & \multicolumn{2}{|c|}{$\%$ won if active } \\
\hline & 103 & 42 & 492 & 571 & 13.7 & 16.1 & 4.4 & 5.9 \\
\hline 2 & 103 & 42 & 1,487 & 402 & 26 & 13.8 & 11.6 & 6.4 \\
\hline 3 & 102 & 41 & 1,049 & 498 & 16.3 & 17.7 & 5 & 7.6 \\
\hline 4 & 101 & 41 & 1,012 & 459 & 31.9 & 27.5 & 12.2 & 11.4 \\
\hline 5 & 102 & 42 & 1,090 & 715 & 26.2 & 22.3 & 8.3 & 9.5 \\
\hline 6 & 103 & 42 & 1,016 & 546 & 25.5 & 23.9 & 7.9 & 9.3 \\
\hline 7 & 101 & 19 & 266 & 45 & 12.1 & 2 & 6.4 & 0.8 \\
\hline 8 & 0 & 8 & 0 & 25 & 0 & 1.8 & 0 & 1.2 \\
\hline 9 & 103 & 42 & 1,308 & 853 & 27.7 & 42.2 & 10.9 & 16.1 \\
\hline 10 & 102 & 40 & 1,149 & 496 & 22.6 & 14.2 & 8.5 & 7 \\
\hline 11 & 101 & 42 & 464 & 211 & 27.4 & 7.9 & 9.6 & 3 \\
\hline 12 & 100 & 42 & 612 & 468 & 26.6 & 35.4 & 8.1 & 15.2 \\
\hline 13 & 93 & 42 & 490 & 605 & 13.7 & 34.4 & 7.9 & 6.5 \\
\hline 14 & 34 & 15 & 121 & 57 & 6.2 & 18.2 & 1 & 2.4 \\
\hline 15 & 22 & 12 & 108 & 66 & 8 & 6.3 & 2.7 & 0.9 \\
\hline 16 & 1 & 14 & 3 & 32 & 1.7 & 4 & 1.7 & 1.7 \\
\hline 18 & 0 & 7 & 0 & 11 & 0 & 16.4 & 0 & 2.8 \\
\hline 18 & 0 & 3 & 0 & 5 & 0 & 7.5 & 0 & 0 \\
\hline 19 & 0 & 1 & 0 & 2 & 0 & 15 & 0 & 12.7 \\
\hline
\end{tabular}

In total 85.3 bnPLN of 52wTB were auctioned, and 90.5bnPLN of 2yB.

while around $41 \%$ are accepted on $2 \mathrm{yB}$. The number of participants on both securities is around 12 , though the $2 \mathrm{yB}$ auctions produce one more winner on average. This finding is not surprising, given that many of the same bidders hold primary dealer status for both securities. The number of bids per bidder is above 8 for 52 -week bills, and over 11 for 2-year bonds, so it appears justified to use economic models in which bidders submit 'demand functions' for multiple items, rather than single-step models with unit demands.

Table 2 shows that there is significant heterogeneity amongst the bidders on both $52 \mathrm{wTB}$ and $2 \mathrm{yB}$. Since primary dealer status is not permanent, some bidders participate in fewer auctions than others due to late entry. ${ }^{11}$ Also, not all bidders participate equally in both types of auction. For 52-week auctions, even if we look at all the bidders who participate in 100 auctions or more, the average percentages won vary considerably: for example, bidder 4 wins on average $12.2 \%$ of the aggregate supply if they participate in an auction, while bidder 1 wins only 4.4\%. Though it would be unsurprising to find a discrepancy of this magnitude within a single auction (and maintain assumptions of symmetry), the fact that the discrepancy persists across 100 auctions suggests that asymmetries may be significant.

From the institutional setup, and the summary of bidders, it is not obvious whether

${ }^{11}$ For example, on $2 y B$, bidder 19 enters late, while bidder 18 is present in early, but later exits. 
a private-value or a common-value model looks more appropriate; interviews with the primary dealers themselves did not yield a consensus either. ${ }^{12}$ The dealers admit that usually $50-80 \%$ of bids that are submitted are in fact forwarded customer bids - but sometimes the dealers change these bids at their own risk. ${ }^{13}$ Furthermore, it is possible that customers perform 'order splitting' in order to hide some of their private information from the dealers: the same client may submit different portions of his demand curve through different dealers. In this context, it is hard to say whether private, or common, values apply: even if each bank serves the same customer pool, each dealer may be observing a different part of each customer's demand.

Currently, there does not exist an econometric methodology that would allow formal testing of common values against private values, in the kind of data I have. Similarly, I am not aware of any complete 'auction for shares' model which would allow both private and common value components to be present simultaneously. ${ }^{14} \mathrm{I}$ will therefore remain agnostic as to which paradigm is correct, but I will evaluate whether the predictions of the two models are consistent with each other. If they are mutually consistent, the theoretical disagreement will have limited significance to the practitioner.

\section{An Application of the HMA Model}

The HMA approach to estimating discriminatory auctions is fully non-parametric, and its conclusions will not be driven by functional form assumptions. A disadvantage of this method is that it does not allow us to explicitly solve for optimal bidding strategies in the uniform price auction. To achieve comparability between the two auction types, I assume that the bidders bid truthfully, and submit their valuations as their actual bids in the uniform price auction. As Ausubel and Cramton (2002) have shown, in most circumstances this assumption is invalid, and even in uniform price auctions some shading will be present. However, truthful bidding in the uniform price auction provides us with an upper bound on the revenue from this auction; with optimally calculated bidding functions, the equilibrium price could be lower than the truthful-bidding price, but not

\footnotetext{
${ }^{12}$ I interviewed 8 of the primary dealers, including the 4 largest ones, and 4 smaller ones.

${ }^{13}$ If the customer asks the dealer to forward a bid at a price which the dealer thinks is too high, the dealer may reduce the price he actually submits on this bid. If the bid gets accepted, the dealer keeps the savings. If the lowered bid gets rejected, whereas a bid at the customer's requested price would have been accepted, the dealer is contract-bound to provide his client with the appropriate amount of securities (out of whatever stock they've won from non-customer bids).

${ }^{14}$ Hortacsu and Kastl (2012) develop a test for common values in auctions for Canadian securities, but that test is specific to their data format. Unfortunately, few datasets contain the kind of information that is necessary to apply their test.
} 
higher. ${ }^{15}$ Hence we will have a one-sided bound on the uniform price revenue, against which to compare the discriminatory auction. If the discriminatory weighted average price is above the truthful-bidding stop-out price in the uniform price auction, then we can conclude that the discriminatory auction is revenue-dominant. In the converse case, the comparison is inconclusive.

\subsection{Simulating the Distribution of the Stop-out Price}

To close the HMA model, a method for calculating the H-distribution is needed. Hortacsu and McAdams (2010) propose a resampling estimator which generates H, without making parametric assumptions, by the following logic. Since the auction model assumes private values, each bidder's submitted demand curve is a function of his signal only; the independence of demands then follows from the assumption of independent signals. As these demand schedules were actually submitted in the auction, they should constitute equilibrium strategies (under the stated assumptions). From the point of view of calculating a stop-out price, the only information we need is every bidder's demand function - the signals themselves are only instrumental.

We can thus simulate the distribution of the stop-out price by repeatedly re-drawing an appropriate number of demand curves and running a discriminatory auction and recording its stop-out price, as illustrated by Figure 2. ${ }^{16}$ If I repeat this procedure sufficiently many times then, given the IID assumptions, the distribution of the simulated stop-out prices will tend to the true distribution H. Since the H-distribution is conditional on each individual bidder's submitted demand schedule, and the equilibrium strategies are specific to each auction, I need to generate a separate H-function for each bidder, in each

${ }^{15}$ Kastl (2011) shows that it may sometimes be optimal to bid above value in a uniform price auction. The intuition is as follows: "Suppose my valuation at $q_{k}$ is $v_{k}\left(q_{k}\right)$, but it is unlikely that the stop-out price occurs at this step. Then I might as well submit a $p_{k}>v\left(q_{k}\right)$, and make it more likely that I do win $q_{k}$ shares in case the stop-out price is in fact $v\left(q_{k}\right)$, rather than risk getting rationed."

Such aggressive bidding is most prevalent at price-quantity combinations which are unlikely to be marginal. Kastl's data-based examples show that overbidding does indeed occur, but only at the first step. In his data this may be significant, as bidders submit demands with only 2.3 steps on average.

In my data, bidders submit over 8 steps in their bid functions, and quantities submitted by bidders at their first few steps are tiny. The likelihood that these bids would be marginal is negligible. It is therefore unlikely that overbidding would occur near the stop-out price in the uniform-price auction. Also, the Ministry of Finance has stated that on 52wTB auctions, it would not ration the marginal bidder anyway. For these reasons, Kastl's argument for overbidding is unlikely to apply in my data to a significant extent.

${ }^{16} \mathrm{~A}$ detailed description of the bootstrapping procedure is provided in Appendix A, and theorems proving the consistency of the estimator can be found in Section IIIb of Hortacsu and MacAdams (2010). 
auction. Figure 3 shows an example of a simulated H-distribution, generated from 1000 repetitions of the resampling procedure.

Figure 2: Illustration of 10 replications of the resampling procedure for $H(p \mid y)$

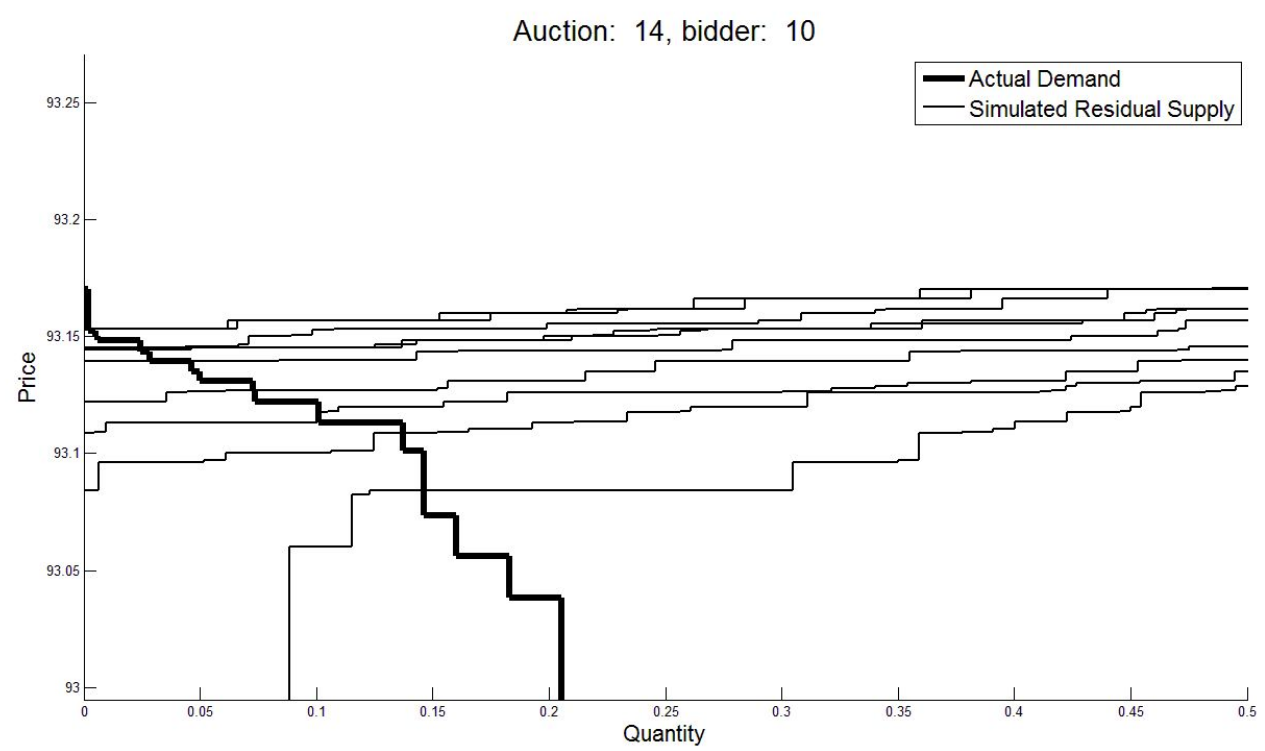

Figure 3: Example of a simulated $H(p \mid y)$ distribution
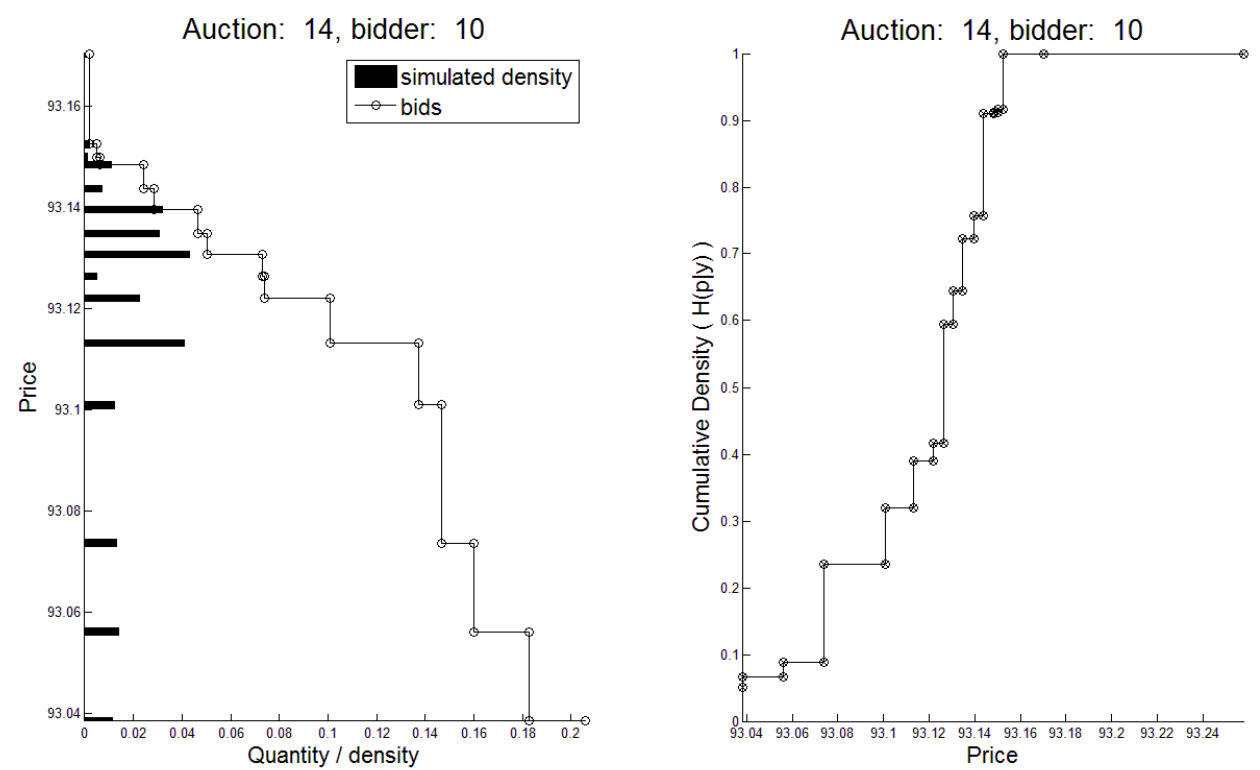

The left-hand panel depicts the bidder's submitted demand curve, and the simulated density at each price at which he submitted a bid. These densities have been aggregated in the right-hand panel, and show the cumulative density - $H(p \mid y)$. Equations (14) and (15), from Appendix A, can then be used to derive the value bounds $\underline{v}$ and $\bar{v}$ for each bidder; the whole procedure is further bootstrapped 200 times to construct error bounds around $\underline{v}$ and $\bar{v}$. 
At the auction level, I make two kinds of revenue comparisons. An ex-post comparison looks at the revenue-difference between a one-shot estimate of the revenue from the uniform price auction using estimated value functions corresponding to the submitted bidder demands. For an ex-ante comparison, for each auction $l$, I draw $n_{l}$ recovered valuation functions (for that auction), ${ }^{17}$ and use those valuations to obtain a stop-out price. I repeat this process 1000 times, and use the data to find the simulated $95 \%$ confidence intervals. ${ }^{18}$ I perform the same calculation for the discriminatory price revenue, and the revenue-difference (for each individual auction round), which allows me to test for revenue-dominance directly.

\subsection{Results from the HMA model}

The complete per-auction results from estimating the HMA model are presented in the Online Appendix. A subset of these results, covering 5 of the 103 auctions on 52wTB are presented in Table 3, with both ex-ante and ex-post results reported. ${ }^{19}$

Table 3: HMA Model Results For First Five 52wTB Auctions

\begin{tabular}{cccc}
\hline $\begin{array}{c}\text { Auction } \\
\text { Number }\end{array}$ & $\begin{array}{c}\text { Ex-Post Revenue } \\
\text { Difference Low Bound }\end{array}$ & $\begin{array}{c}\text { Ex-Ante Revenue Diff. } \\
\text { Low Bound }\end{array}$ & $\begin{array}{c}\text { Ex-Ante Revenue Diff. } \\
\text { High Bound }\end{array}$ \\
\hline \hline 1 & $0.1273[0.0703,0.2048]$ & $0.0346[0.0346,0.0346]$ & $0.0352[0.0352,0.0352]$ \\
2 & $0.0341[0.0176,0.0684]$ & $0.0283[0.0283,0.0283]$ & $0.0288[0.0288,0.0288]$ \\
3 & $0.0399[0.0206,0.0762]$ & $0.0180[0.0180,0.0180]$ & $0.0185[0.0185,0.0185]$ \\
4 & $0.0129[-0.0005,0.0221]$ & $0.0070[0.0070,0.0070]$ & $0.0075[0.0075,0.0075]$ \\
5 & $0.0327[0.0211,0.0497]$ & $0.0200[0.0200,0.0200]$ & $0.0206[0.0206,0.0206]$ \\
\hline \multicolumn{3}{l}{ Positive differences indicate that discriminatory auction is revenue-dominant. } \\
\multicolumn{3}{l}{ Bootstrapped 95\% confidence intervals in square brackets. } \\
\hline
\end{tabular}

Revenue differences in Table 3 are all positive, indicating that the discriminatory auction is revenue-superior. The majority of the confidence intervals also do not encompass zero, suggesting that the revenue differences are significant at the $95 \%$ level.

An overall summary of the average revenue performance and auction-by-auction dominance results are shown in Table 4 . In the case of average revenues, I have again only reported the lower-bound difference, as the upper-bound difference is almost identical,

${ }^{17}$ This is equivalent to randomly drawing the appropriate number of participants, within each auction, and having them play one round of the auction, assuming that their bidding and valuation functions remain unchanged.

\footnotetext{
${ }^{18}$ Ex-ante simulations offer a more general prediction, comparing how both auctions would perform on average, while the ex-post comparison looks at a single realized outcome only.

${ }^{19}$ This table does not report the ex-post revenue difference upper bound, since it is different from the low-bound only at the third significant figure, or less. The full results are available upon request.
} 
with the difference appearing only after 3 significant figures. For both securities, the average revenue differences are positive both ex-post and ex-ante, indicating that the discriminatory auction is revenue superior. Though the actual numbers are small, they all reject revenue equivalence in a t-test with p-values $<0.001$. In ex-post terms, the discriminatory auction gives $0.011 \%$ higher revenue on $52 \mathrm{wTB}$, and $0.024 \%$ more on $2 \mathrm{yB}$.

Table 4: Revenue summary for the HMA model

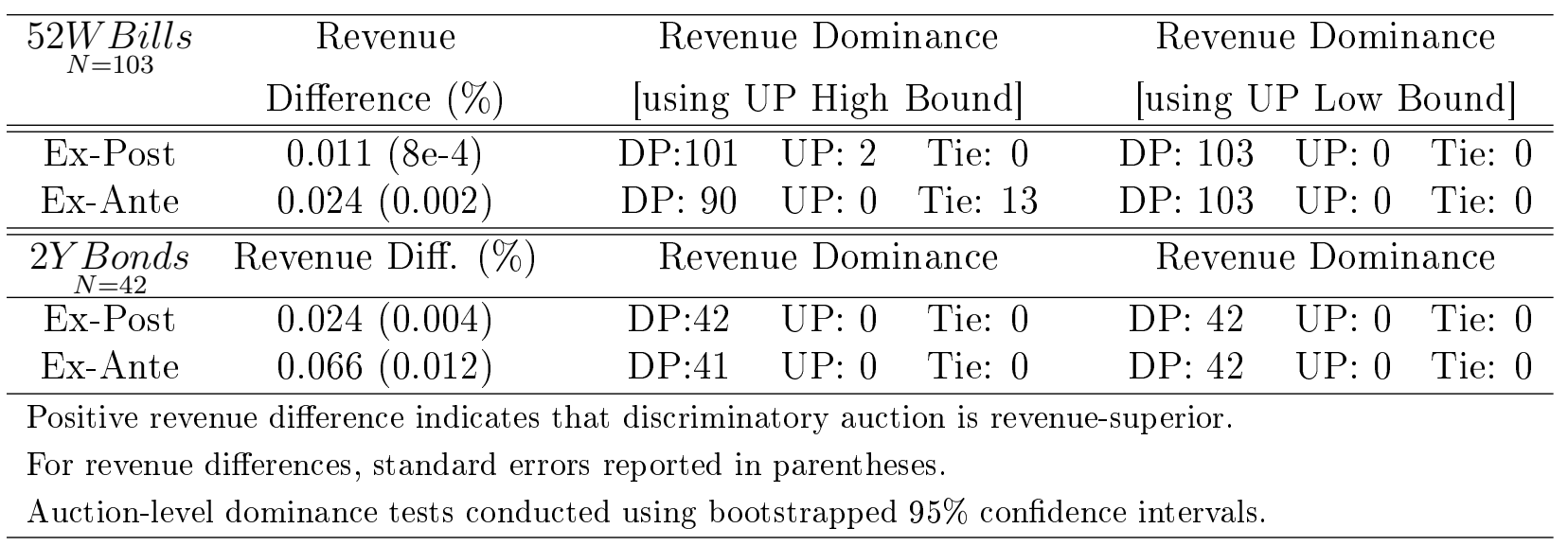

The differences in ex-ante terms are larger: $0.024 \%$ on $52 \mathrm{wTB}$ and $0.066 \%$ on $2 \mathrm{yB}$. These percentages are small, and despite the large volume of securities sold, the differences are unlikely to have economic significance. In monetary terms, per annum, the ex-post differences translate into $4.5 \mathrm{mPLN}(\sim \$ 1.4 \mathrm{~m})$ for the $52 \mathrm{wTB}$, and $8.2 \mathrm{mPLN}(\sim \$ 2.5 \mathrm{~m})$ for $2 \mathrm{yB}$. Looking at auction-level dominance results, which uniform price revenue bound is used does influence the outcome: when using the low-bound revenue from the uniform price auction, there are no ties, and the discriminatory auction is dominant in every auction, on both securities, both ex-post and ex-ante. Using high-bound estimates of uniform price revenue, however, generates a tie in a few auctions, in particular on the 52 wTB ex-ante. Nonetheless, the model never generates an outcome in which the uniform price auction is revenue-dominant.

When interpreting these results, it is important to recall that the revenue calculations for the uniform price auction are done on the assumption of truthful bidding, which is likely inflating the revenue and decreasing the revenue gap. If in practice bidders were to shade, the revenue differences would be larger. On the whole, the HMA model concludes that the discriminatory price auction is revenue-superior.

\section{An Application of the FPV Model}

To connect the FPV moment-conditions from Section 2.2 to the data, a method for estimating the conditional expectation of $V$ is needed; this in turn requires a parametric specification of the F-distributions, and a procedure for estimating their parameters. To fix notation, let 1 be the subscript for variables specific to the l-th auction out of a total 
of $\mathrm{L}$ auctions, so $l \in\{1, \ldots, L\}$. The number of bidders, $N_{l}$, and other auction-specific characteristics, $Z_{l}$, vary by auction. Following FPV, I assume that the pairs of random variables $\left(N_{l}, Z_{l}\right)$ are independently and identically distributed, for $l=1, \ldots, L$.

Next, I assume that the true value of the bonds, $V_{l}$, is dependent of $Z_{l}$, but independent of $N_{l}$ : auction-specific characteristics influence the bonds' value, but the number of participating bidders does not. Conditional on $Z_{l}$, the realizations of the true values, $V_{1}, \ldots, V_{l}$, are assumed independent. Similarly, a bidder i's signal in auction $1, \mathrm{~S}_{i l}$ is assumed independent of $\mathrm{N}_{l}$, but dependent on both $V_{l}$ and $Z_{l}$. Finally, assume that the signals $S_{i l}, \ldots, S_{i L}$ are independent conditional on $\left(V_{l}, Z_{l}\right)$, and also that $S_{i l}$ is independent of $S_{i l^{\prime}}$ conditional on $Z_{l}$ and $\mathrm{Z}_{l^{\prime}}$, for all $l \neq l^{\prime}{ }^{20}$

To estimate the distribution of $V$, FPV use a parametric approach. Denote the distribution of $V_{l}$, conditional on $Z_{l}=z$ as $F_{V \mid Z}\left(. \mid z, \theta_{1}\right)$, where $\theta_{1}$ is the set of parameters characterizing the distribution. Analogously, denote the distribution of $S_{i l}$, conditional on $V_{l}=v$ and $Z_{l}=z$ as $\mathrm{F}_{S \mid V, Z}\left(. \mid v, z, \theta_{2}\right)$, with $\theta_{2}$ denoting parameters specific to this distribution. Given these two distributions, we can recursively derive the distribution of the signal $\mathrm{S}_{i l}$ itself, conditional only on $Z=z$; I denote this $F_{s \mid Z}(. \mid \theta)$, with $\theta=\left(\theta_{1}, \theta_{2}\right)^{\prime}$. I assume that the true value of the parameters describing my data is $\theta^{0}$, and it is these parameters I wish to estimate.

\subsection{Parametric specification, and density estimation in the FPV model}

The $F_{V \mid Z}$ distribution selected by FPV is a hybrid of gamma and Weibull distributions, while $F_{S \mid V, Z}$ is exponential:

$$
\begin{aligned}
F_{v \mid z}\left(v \mid z_{l}, \theta\right) & =\int_{0}^{v} \gamma u^{\gamma-1} \frac{\beta^{\alpha}}{\Gamma(\alpha)} u^{\gamma(\alpha-1)} \exp \left(-\beta u^{\gamma}\right) d u \\
F_{S \mid V Z}\left(s \mid v, z_{l}, \gamma\right) & =1-\exp \left(-s v^{\gamma}\right) .
\end{aligned}
$$

From the definition of $F_{V}$, it follows that $E\left(v^{\gamma}\right)=\frac{\alpha}{\beta}$, and combining this with $F_{S}$, the expected value of $V$ as well as the uniform price auction cutoff price can be analytically expressed as: $:^{21}$

$$
\begin{aligned}
E\left[V_{l} \mid S_{1 l}=s_{1 l}, \ldots, N_{l}=n_{l}, Z_{l}=z_{l}\right] & =\frac{\Gamma\left(n_{l}+\alpha_{l}+\frac{1}{\gamma}\right)}{\Gamma\left(n_{l}+\alpha_{l}\right)}\left(\beta_{l}+\sum_{i=1}^{n_{l}} s_{i l}\right)-\frac{1}{\gamma} \\
p_{l}^{0-\text { uniform }} & =\frac{1}{1+\frac{1}{\gamma^{0}}} E\left\{V_{l} \mid \ldots\right\} .
\end{aligned}
$$

${ }^{20}$ These assumptions eliminate intertemporal dependence of bidders' signals, which is necessary for the derivation of FPV's estimators.

${ }^{21}$ The derivation is presented in FPV (2002), appendix C. 
The final step in implementing the FPV procedure is to estimate the signals $s_{i}$ from the data. To this end, I assume that each bidder has an optimal bidding strategy of $q(p, s, n, z \mid \theta)$ - this denotes the quantity which the bidder demands at price $\mathrm{p}$, conditional on signal s, auction-specific covariates $\mathrm{z}$, and the true parameters equal to $\theta^{0}$. Recall that in Section 2.2, I assumed that the equilibrium bidding functions are strictly monotonic this means they admit an inverse, $q^{-1}(p, s, n, z \mid \theta)$. Given this notation, define $G(q \mid n, z, p)$ as the distribution function of the equilibrium demand, conditional on $Z=z, V=v$ :

$$
\begin{aligned}
G(q \mid n, z, p) & =\operatorname{Pr}\left(q\left(p, S_{i l}, N_{l}, Z_{l}, \theta^{0}\right) \leq q \mid N_{l}=n_{l}, Z_{l}=z_{l}\right) \\
& =1-F_{S \mid Z}\left(q^{-1}\left(p, S_{i l}, n_{l}, z_{l}, \theta^{0}\right) \mid z, \theta^{0}\right) \\
\text { hence } & : \\
S_{i l} & =-\frac{\beta \ln G\left(q_{i l} \mid n, z, p\right)}{\alpha} .
\end{aligned}
$$

This establishes a connection between the distribution of (equilibrium) demands and the distribution of signals. Since I observe individual bidder's bids, and these are assumed to be part of their equilibrium demands, I can use this data to construct the distribution function G. I follow FPV in doing this non-parametrically using kernel-density estimation, such that:

$$
\hat{G}(q \mid n, z, p)=\frac{\sum_{l=1}^{L} K\left(\frac{n-n_{l}}{h_{N}}, \frac{z-z_{l}}{h_{Z}}\right) \frac{1}{n_{l}} \sum_{i=1}^{n_{l}} 1_{\left(q_{i l p} \leq q\right)}}{\sum_{l=1}^{L} K\left(\frac{n-n_{l}}{h_{N}}, \frac{z-z_{l}}{h_{Z}}\right)}
$$

where $K(.,$.$) is a multivariate kernel, h_{N}$ is the bandwidth parameter associated with the number of bidders, and $h_{Z}$ is a vector of bandwidths.

Using equations (8), (10) and (11), the Euler equation in (7) can be re-written in terms of estimable parameters. Replacing the theoretical expectation with an empirical average, I obtain a moment condition which can be used for estimation:

$$
\begin{aligned}
0 & =\frac{1}{L} \sum_{l=1}^{L}\left\{w\left(N_{l}, Z_{l}\right) \cdot\left(N_{l}-1\right) \cdot 1_{\left[P_{l}^{0} \leq p\right]} \cdot\left[E\left[V_{l} \mid S_{n_{i} l}=\hat{s}_{n_{i} l}, N_{l}=n_{l}, Z_{l}=z_{l}\right]-p\right)\right\}- \\
& -\frac{1}{L} \sum_{l=1}^{L}\left[w\left(N_{l}, Z_{l}\right)\left(p-P_{l}^{0}\right) \cdot 1_{\left[P_{l}^{0} \leq p\right]}\right]
\end{aligned}
$$

where $w(.,$.$) is a weighting function, dependent on the auction-specific covariates. Equa-$ tion (12) should be satisfied for any $p \in[0, \infty)$, giving a continuity of moment conditions. For practical purposes, I only evaluate these moment conditions at the observed stop-out prices, which gives me 103 moment conditions for 52wTB, and 42 moment conditions for 
2yB. I perform the estimation separately for both securities. ${ }^{22}$

Replacing the true parameters in equation (12) by their estimated counterparts, the estimated uniform price cutoff becomes:

$$
\widehat{p_{l}^{\text {uniform }}}=\frac{1}{1+\frac{1}{\hat{\gamma}}} \frac{\Gamma\left(n_{l}+\hat{\alpha}_{l}+\frac{1}{\hat{\gamma}}\right)}{\Gamma\left(n_{l}+\hat{\alpha}_{l}\right)}\left(\hat{\beta}_{l}+\sum_{i=1}^{n_{l}} \hat{\beta}_{l}\left(\frac{1}{\hat{G}^{\frac{1}{\alpha_{l}}}\left(x_{i l p} \mid n_{l}, z_{l}, p\right)}-1\right)\right) \cdot-\frac{1}{\hat{\gamma}}
$$

From equation (13) we see that the uniform stop-out price is a constant fraction of the common value. While FPV require $\gamma$ to be constant across auctions, I place no such restriction in my estimates.

Inference on $\theta$ in the FPV model is performed using Newey and McFadden's (1989) results on two-stage estimators; the details of applying these results in this case are discussed in Appendix $\mathrm{C}$ of Fevrier et al. (2002). In addition to testing for the significance of the parameters in the gamma-exponential configuration, I will simulate confidence bounds around stop-out price in the uniform price auction, analogously to Section 4.2 for the HMA model. For each auction $l$, I will draw $n_{l}$ of the recovered individual signals, calculate the $V_{l}$ from these signals, and consequently the stop-out price. I will repeat the procedure 1,000 times for each auction, and hence obtain the appropriate standard deviations and simulated error bounds.

\subsection{Results from the FPV Model}

For the estimation of the parameters for the FPV model, I ran a separate model for each security type. The reason for this is twofold. Firstly, given that the two securities differ in the role they play in investors' portfolios, there is no a-priori reason to expect the same parameters to hold across both types. Secondly, the relevant covariates for the estimation vary for the two security types: while on $2 \mathrm{yB}$ maturity is a relevant variable, this is not the case for $52 \mathrm{wTB} .{ }^{23}$ Thus for $52 \mathrm{wTB}$, I have included a covariate for the secondary price, as well as a measure of 'inflation expectations one year ahead'; for $2 \mathrm{yB}$,

\footnotetext{
${ }^{22}$ For estimating the model, I re-scale all the face-value prices to 1 as this eliminates some computational problems with the un-scaled model. Subsequent to estimation, the results are re-scaled back to 100, for easier comparability. The same approach was used by Castellanos \& Oviedo (2006), who apply the FPV model to Mexican data.

${ }^{23}$ The reason why maturity varies across auctions for 2-year bonds is that usually four auctions are held for the same line of bonds. Nominally all these bonds are classified as 2-year securities, but the effective maturity in certain auctions is less. The first set of bonds issued in a given line has a maturity of 2 years, the second issue a maturity of 1 year 11 months, etc. For 52-week bills, the maturity is the same in all auctions, and hence doesn't provide any explanatory power on this subset of data.
} 
Table 5: FPV Estimated Parameters

\begin{tabular}{cccc}
\hline 52-Week Bills & $\alpha$ & $\beta$ & $\gamma$ \\
\hline Constant & $324.1(524.6)$ & $1.11 \mathrm{e} 10^{\star}(341.9)$ & $-4.19 \mathrm{e} 3^{\star}(1.61 \mathrm{e} 3)$ \\
Secondary Market Price & $-284.3(489.3)$ & $-1.15 \mathrm{e} 10^{\star}(354.3)$ & $4.72 \mathrm{e} 3^{\star}(1.60 \mathrm{e} 3)$ \\
Inflation Expectations & $-17.3(16.3)$ & $1.32 \mathrm{e} 6^{\star}(0.53)$ & $13.5(18.1)$ \\
\hline 2-Year Bonds & $\alpha$ & $\beta$ & $\gamma$ \\
\hline Constant & $-210.7^{\star}(1.33)$ & $4.20 \mathrm{e} 5^{\star}(0.58)$ & $-51.0^{\star}(0.42)$ \\
Secondary Market Price & $222.1^{\star}(1.39)$ & $-4.57 \mathrm{e} 5^{\star}(0.85)$ & $209.9^{\star}(0.45)$ \\
Maturity & $0.118^{\star}(0.025)$ & $0.73^{\star}(0.002)$ & $-0.123^{\star}(1.7 \mathrm{e}-5)$ \\
Inflation Expectations & $-22.7^{\star}(5.94)$ & $2.54^{\star}(0.42)$ & $6.74^{\star}(1.54)$ \\
\hline Estimates reported (std.error in brackets). & & \\
Coefficients significantly different from zero at the $95 \%$ confidence level are denoted by ${ }^{\star}$. \\
\hline
\end{tabular}

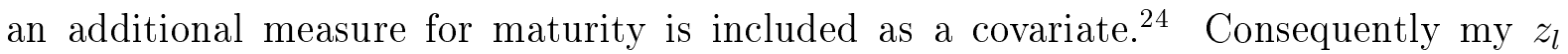
vector is has dimensions of $1 \times 2$ in the case of $52 \mathrm{wTB}$, and $1 \times 3$ in the case of $2 \mathrm{yB}$. For the kernel function, I follow FPV in using a multiplicative Epanechnikov kernel, and bandwidth is selected using Silverman's rule of thumb. Parameter estimates from my model are presented in Table 5.

For $2 \mathrm{yB}$, all parameters in the $\alpha, \beta$ and $\gamma$ vectors are significantly different from zero, whereas for $52 \mathrm{wTB}$ none of the $\alpha$ parameters test as significant. Similarly to previous papers using the FPV methodology, such as Fevrier et al. (2002) and Castellanos and Oviedo (2006), the average value of $\gamma$ is significantly larger than $1 .^{25}$ Based on these parameters, I can simulate per-auction revenues from the two auction formats, as well as the inferred common value. Examples of this are given in Table 6. Ex-ante and expost prices and values are generated using an analogous methodology to Table 4, and as explained in footnote 18; the only difference is that instead of resampling individual bidding and value functions, in the FPV model I resample signals instead.

A complete summary of the per-auction results is relegated to the Online Appendix, while overall performance of both auction types is summarized in Table 7 . The average revenue difference figures for both securities, both ex-post and ex-ante, are positive, indicating that the discriminatory price auction is again revenue-dominant. Compared to the HMA model, the FPV revenue differences are much larger, giving the discriminatory auction a $0.12 \%$ advantage on $52 \mathrm{wTB}$, and $1.50 \%$ on $2 \mathrm{yB}$ ex-post. A t-test for revenue

\footnotetext{
${ }^{24}$ The data on secondary market prices was obtained from the Polish Ministry of Finance, and the data on inflation expectations was supplied by Reuters.

${ }^{25}$ The average $\gamma$ for all $52 \mathrm{wTB}$ auctions is 321.1 with standard error of 4.8 ; the average for all $2 \mathrm{yB}$ auctions is 56.1 with standard error 0.97. In both cases, a t-test for $\gamma=1$ rejects with p-value $<0.001$.
} 
Table 6: FPV Model Results For First Five 52wTB Auctions

\begin{tabular}{cccccc}
\hline $\begin{array}{c}\text { Auction } \\
\text { Number }\end{array}$ & $\begin{array}{c}\text { Common } \\
\text { Value }\end{array}$ & $\begin{array}{c}\text { Ex-Post } \\
\text { DP Revenue }\end{array}$ & $\begin{array}{c}\text { Ex-Post } \\
\text { UP Revenue }\end{array}$ & $\begin{array}{c}\text { Ex-Post Revenue } \\
\text { Difference }(\%)\end{array}$ & $\begin{array}{c}\text { Ex-Ante Revenue } \\
\text { Difference (\%) }\end{array}$ \\
\hline \hline 1 & 93.72 & 93.58 & 93.37 & 0.23 & $0.17[0.00,0.25]$ \\
2 & 93.74 & 93.43 & 93.39 & 0.04 & $0.04[0.01,0.05]$ \\
3 & 93.72 & 93.46 & 93.37 & 0.1 & $0.09[0.08,0.11]$ \\
4 & 93.8 & 93.51 & 93.45 & 0.07 & $0.06[0.04,0.08]$ \\
5 & 93.95 & 93.57 & 93.6 & -0.02 & $-0.03[-0.04,-0.01]$ \\
\hline
\end{tabular}

Means reported. For ex-ante revenue difference, simulated 95\% CI in square brackets

Table 7: Revenue summary for the FPV model

\begin{tabular}{ccccc}
\hline $52 W$ Bills & Revenue Difference (\%) & \multicolumn{3}{c}{ Revenue Dominance } \\
\hline \hline Ex-Post & $0.121(0.013)$ & DP: 93 & UP: 10 & Tie: 0 \\
Ex-Ante & $0.127(0.013)$ & DP: 88 & UP: 0 & Tie: 5 \\
\hline \hline $2 Y \underset{N=42}{\text { Bonds }}$ & Revenue Difference (\%) & \multicolumn{3}{c}{ Revenue Dominance } \\
\hline Ex-Post & $1.50(0.060)$ & DP: 42 & UP: 0 & Tie: 0 \\
Ex-Ante & $1.46(0.059)$ & DP: 42 & UP: 0 & Tie: 0 \\
\hline
\end{tabular}

Positive difference indicates that discriminatory auction is revenue-superior.

For revenue differences, standard errors reported in parentheses.

Auction-level tests conducted using bootstrapped $95 \%$ confidence intervals.

equivalence, on both maturities, rejects with p-values $<0.001$. The divergence between ex-post and ex-ante revenue differences, however, are smaller than in the HMA model, which suggest that the FPV model is less sensitive to resampling. ${ }^{26}$ In monetary terms, the per-annum revenue differences are $49 \mathrm{mPLN}(\sim \$ 15.1 \mathrm{~m})$ for $52 \mathrm{wTB}$, and $509 \mathrm{mPLN}$ $(\sim \$ 156 \mathrm{~m})$ for the $2 \mathrm{yB}$. The Polish budget deficit over the period of my sample was around $30 \mathrm{bnPLN}$ per annum, so the figures from the FPV model would indicate that the influence of auction format could have some economic significance. ${ }^{27}$

At the individual auction level, both ex-post and ex-ante the discriminatory price auction is revenue-dominant in all 42 auctions for $2 \mathrm{yB}$. On the $52 \mathrm{wTB}$ sample, the uniform price auction is revenue-superior in less than $10 \%$ of the cases, both ex-post and ex-ante. The discriminatory price auction revenue-dominates in over $90 \%$ of the auctions ex-post, and in approximately $85 \%$ ex-ante, with ties occurring in only $5 \%$ of cases.

\footnotetext{
${ }^{26}$ This insensitivity to resampling also suggests that asymmetries between bidders are unlikely to significantly influence revenue in the FPV model.

${ }^{27}$ The annualized revenue-differences on $52 \mathrm{wTB}$ would amount to approximately $0.17 \%$ of the budget deficit; the corresponding figure for $2 \mathrm{yB}$ is $1.7 \%$.
} 


\section{Interpretation and Comparison}

Since the two models that I analyze are not directly comparable in terms of their parameters, the comparisons I can perform are inherently reduced-form, and evaluate the output from the counterfactual simulations in both models. To fix terminology, say that the results from the two models differ if they don't suggest the same dominance outcome, and say that the results are inconsistent if their conclusions are contradictory. The difference here is how I treat the cases when either model can't produce a definite dominance conclusion. ${ }^{28}$

Table 8 shows a summary comparing the two models ex-post, ${ }^{29}$ as well as in two possible ex-ante scenarios, depending on whether the low- or high-bound estimates of the uniform price revenue from the HMA model are used. In ex-post terms, the models are only inconsistent in $10 \%$ of the $52 \mathrm{wTB}$ sample. ${ }^{30}$ Looking at simulated ex-ante scenarios, I find that the models differ most when the HMA uniform price revenue is evaluated at the higher bound, since in this case the HMA model generates the highest number of ties, as indicated by Table 4 . In this case, HMA and FPV disagree in $17 \%$ of the $52 \mathrm{wTB}$ sample, and on $2 \%$ of the $2 \mathrm{yB}$ sample. The extent of inconsistency between the two models does not depend on where the HMA uniform price revenue is estimated, and stays at $9 \%$ for the $52 \mathrm{wTB}$ sample, while there is no inconsistency on $2 \mathrm{yB}$. On aggregate, the models are inconsistent in at most $7 \%$ of cases, and disagree in at most $13 \%$ of the data. In terms auction-level revenue dominance, for the majority of the sample, both models agree that the discriminatory auction performs better.

Table 8: Summary of disagreement between HMA and FPV models

\begin{tabular}{|c|c|c|c|c|c|}
\hline & $\begin{array}{c}\text { Ex-Post } \\
\text { (inconsistent) }\end{array}$ & \multicolumn{2}{|c|}{$\begin{array}{c}\text { Ex-Ante Using } \\
\text { HMS UP High Bound }\end{array}$} & \multicolumn{2}{|c|}{$\begin{array}{c}\text { Ex-Ante Using } \\
\text { HMA UP Low Bound }\end{array}$} \\
\hline 52 WeekBills & $10 \%$ & $17 \%$ & $9 \%$ & $9 \%$ & $9 \%$ \\
\hline 2 Year Bonds & $0 \%$ & $2 \%$ & $0 \%$ & $0 \%$ & $0 \%$ \\
\hline Overall & $7 \%$ & $13 \%$ & $6 \%$ & $3 \%$ & $7 \%$ \\
\hline
\end{tabular}

The average prices summarized in Table 9 are all very close to each other. In each

\footnotetext{
${ }^{28}$ If one model cannot decide revenue dominance, while the other can, I say that they "differ" on this particular auction. On the other hand, if one model suggests that UP dominates DP, while the other says that DP dominates UP, I say that these conclusions are "inconsistent".

${ }^{29}$ For the ex-post comparison, I only show one case, since for this comparison it makes no difference whether the HMA uniform-price revenue is evaluated at the lower or upper bound.

${ }^{30}$ There are no cases where the models disagree, since ex-post both the HMA and FPV models produce a definite conclusion.
} 
case, the FPV model generates lower uniform price predictions than HMA, though on the 52wTB sample these differences are small. On the 2yB sample the FPV model's predictions are over $1 \%$ different from HMA, and given the higher volume on this security, this difference has more economic significance. Nonetheless, on average both models agree that there would be no revenue-advantage from switching to the uniform price auction.

Table 9: Comparison of prices, values and revenues

\begin{tabular}{lcc}
\hline & 52 week bills & 2 year bonds \\
\hline Number of Auctions & 103 & 42 \\
\hline Secondary Market Price & $94.78(1.16)$ & $89.57(1.95)$ \\
\hline Ex-Post DP Price & $94.80(1.16)$ & $89.11(2.23)$ \\
Ex-Post HMA UP Price & $94.79(1.16)$ & $89.09(2.23)$ \\
Ex-Post FPV UP Price & $94.66(1.17)$ & $87.77(2.35)$ \\
Ex-Post FPV Value & $94.97(1.16)$ & $89.34(2.28)$ \\
\hline Ex-Ante DP Price & $94.79(1.17)$ & $89.08(2.23)$ \\
Ex-Ante HMA UP Price & $94.76(1.17)$ & $89.02(2.26)$ \\
Ex-Ante FPV UP Price & $94.66(1.21)$ & $87.78(2.35)$ \\
Ex-Ante FPV Value & $94.97(1.16)$ & $89.35(2.28)$ \\
\hline Means reported (standard deviations in brackets). \\
DP Price is the 'weighted average price' in the discriminatory auction. \\
UP Price is the stop-out price in the uniform price auction. \\
\hline
\end{tabular}

Curiously, for $52 \mathrm{wTB}$, the average discriminatory auction price is above the secondary market equivalent, though by only a small amount. This result is driven by a handful of small bids at very high prices, which constitute roughly $10 \%$ of all bids. ${ }^{31}$ This anomaly is likely a data problem. From discussions with the bidders, it emerged that the secondarymarket prices for 52wTB are inaccurate, since the liquidity on these bonds is very low, and most of them are kept to term; no trade actually takes place at the quoted prices. ${ }^{32}$

The common value estimated using the FPV model is above both the discriminatory price, and the uniform price upper-bound in the HMA model - so overbidding due to winners' curse is unlikely. On $2 \mathrm{yB}$, the FPV common value lies below the secondary market price, which may indicate that the auction participants have arbitrage opportunities. Conversely, on the $52 \mathrm{wTB}$, the common value is considerably above the market price, which is consistent with most of the primary auction participants wanting to keep them to term.

The conclusions of my paper, as compared with the past literature on the subject

\footnotetext{
${ }^{31}$ From my discussion with auction participants there appeared a consensus that these high bids were usually directly forwarded customer bids, which the brokers were explicitly requested not to adjust.

${ }^{32}$ The Ministry of Finance requires dealers to quote prices for all maturities of bonds that they hold, even if none are traded at that price. Doing so is a pre-requisite for obtaining, and renewing, a license.
} 
is described in Table 10. Results from Hortacsu's (2002) model showed a large revenue superiority for discriminatory price, but due to the large variability of the predictions, the results were not significant. The HMA model as applied by Hortacsu and McAdams (2010) found much smaller revenue differences using that same dataset, and despite a new method of error estimation, no significant revenue ranking emerged. Kang and Puller (2006) apply the Hortacsu (2002) model to find small differences in favor of the discriminatory auction in South Korea, and these test as significant. However, their comparison is not direct: they benchmark both the discriminatory and uniform price auctions against the common a multi-unit Vickrey auction. It is unclear whether this method introduces a bias. ${ }^{33}$

Table 10: Past Results of Structural Models of T-bill auctions

\begin{tabular}{llll}
\hline Author(s) & Method & Country & Revenue-superiority \\
\hline \hline Hortacsu (2002) & H & Turkey & D by 14\%, not significant \\
HMA (2010) & HMA & Turkey & UP by $0.1 \%$, not significant \\
Kastl (2011) & H-type & Cz. Rep & UP price may exceed truthful bidding \\
Kang \& al. (2008) & H & Korea & D 0.1\%, significant \\
\hline FPV (2002) & FPV & France & D by $2 \%$, significant \\
Castellanos \& al. (2006) & FPV & Mexico & UP by $2 \%$, significant \\
Armantier \& al. (2006) & other & France & UP by $4.8 \%$, significant \\
\hline This Paper & HMA & Poland & D by up to $0.07 \%$, significant \\
This Paper & FPV & Poland & D by up to $1.5 \%$, significant \\
\hline \hline
\end{tabular}

H indicates the model of Hortacsu (2002), HMA and FPV as used in this paper

Uniform price denoted by "UP", and discriminatory auction by "D".

The model used by Armantier \& Sbai is parametric and includes risk aversion.

All of the other applications of the FPV model, or other semi-parametric models, yield conclusions of significant differences. The magnitude of my estimated revenue differences is similar to that in Castellanos and Oviedo (2006), who directly apply the FPV model to Mexican data, and find the uniform price auction revenue-superior. There is a disagreement between the FPV and Armantier and Sbai (2006) papers, which both use French data. The cause of this disagreement may follow from the different economic models that underlie the econometrics. While the FPV estimation is based on Wilson's (1979) economic model, the economic theory behind the structural model in Armantier and Sbai (2006) builds on that of Wang and Zender (2002).

The magnitudes of revenue differences from my application of the two models are comparable to those from other statistically significant results obtained in other countries,

\footnotetext{
${ }^{33}$ The reason for an indirect comparison is that Kang and Puller observe, data from both uniformprice and discriminatory auctions, but across different time periods. Since the Hortacsu (2002) model does not admit an optimal bidding solution for either auction type, their alternative is to use an auction where 'truthful bidding' is optimal - the Vickrey auction satisfies this condition.
} 
suggesting that the performance of these models is relatively stable. Hence their mutual comparison can be considered meaningful. Admittedly, my analysis does not rule out the possibility that a model different from HMA and FPV could reach a different result. Nonetheless, this is the first time that multiple models, with diverging economic and econometric assumptions, are compared on a common dataset on divisible goods auctions. The finding that they reach the same conclusion is therefore not trivial.

The major limitation of my analysis is that it evaluates revenues under the assumption that only the auction rules change, and nothing else in the regulatory framework does. If a switch of auction rule were enacted, it is likely that other aspects of the auction setup would also change. Back and Zender (2001) mention that collusion may be more easily sustained under uniform price rules, and the Ministry of Finance might want to change the market rules to counteract that effect. Within the current legislative framework, one tool readily available to that end is the ability to restrict supply, if demand is low. ${ }^{34}$ A more drastic remedy would be to change the participation rules in the auction, for example, by making a larger number of dealer license available, or abolishing the dealer system altogether. This could have significant consequences for new bidder participation, beyond those who are already submitting client-bids under the current dealer system.

\section{Conclusions}

I use a dataset on two maturities of Polish treasury bills to evaluate the performance of two structural econometric models of share auctions. To my knowledge, this is the first consistent application of the HMA and FPV models on a single dataset, and also the first time either of them has been run on Polish data. Both models suggest that the discriminatory price setup is revenue-superior over the uniform price auction.

My strongest finding is that from the FPV model, the discriminatory auction has a revenue advantage of roughly $1.5 \%$ on 2 year bonds, and $0.12 \%$ on 52 week bills. The predictions from the HMA model confirm the revenue-superiority of the discriminatory price auctions, albeit by a smaller margin.

In a direct comparison of predictions, I find that the models agree in over $80 \%$ of all auctions, and propose contradictory conclusions in only $7 \%$ of the data. ${ }^{35}$ The agreement between two models based on significantly different assumptions can inspire confidence that the conclusions are indeed data-driven, rather than modeling artifacts. In the case of Poland, during my sample, the data did not recommend the switching of auction format.

\footnotetext{
${ }^{34}$ In the Back and Zender (2001) model, endogenous supply selection eliminates the collusive-seeming equilibria in uniform price auctions.

${ }^{35}$ In my conversations with the Ministry of Finance, at the time of the initial drafting of this paper, it emerged that their primary area of concern for evaluating the auction rules was revenue performance.
} 


\section{Appendix A: Further Details on the HMA Model}

\subsection{Discrete Version of the Value Recovery Equation and Bounds}

The Euler equation (4) was derived under the assumption of continuous bidding functions, while the data I use is indeed discrete. Hortacsu and McAdams (2010) offer a discrete analogue to equation (4), with the additional caveat that the value function is no longer point-identified. A detailed derivation and proofs are presented in Section 2 of Hortacsu and McAdams (2010), but below I outline a few key steps using my notation, for easier interpretation. Let the quantity grid be discrete with $K$ steps, such that $y_{1}<y_{2}<\ldots<y_{K}$, and let $p(q)=y^{-1}(p)$ denote the inverse of the optimal bidding function. ${ }^{36}$ Furthermore, let $\Delta$ be a price or value increment such that $0<\Delta \leq \min \left[p\left(y_{k}\right)-p(y), p\left(y_{k+1}\right)-p(y)\right]$. Then the upper and lower bounds for the value function $v(y)$, with $y \in\left[y_{k}, y_{k+1}\right]$ are given by:

$$
\begin{aligned}
& v(y) \leq \bar{v}(y, p(.))=p(y)+\Delta+\frac{\Delta \sum_{q=y_{k}}^{y} H(q ; p(y))}{\sum_{q=y_{k}}^{y}[H(q ; p(y)+\Delta)-H(q ; p(y))]}, \\
& v(y) \geq \underline{v}(y, p(.))=p(y)+\frac{\Delta \sum_{q=y}^{y_{k+1}} H(q ; p(y))}{\sum_{q=y}^{y_{k+1}}[H(q ; p(y))-H(q ; p(y)-\Delta)]} .
\end{aligned}
$$

This pair of equations is derived by looking at the incentives from increasing an individual bid up or down by an increment. The upper and lower bounds are the two cutoffs between which such a deviation, either way, is not profitable.

Note that when we move towards the continuous case, such that $y_{k+1} \rightarrow y_{k}$ and $\Delta \rightarrow 0$, the above bounds collapse into each other, and we recover equation (4). In my application of this model, I chose $\Delta$ to correspond to the smallest recorded price increment recorded in my data (for each security type), and used equations (14) and (15) at each price-quantity pair to calculate the value bounds.

\subsection{Details of the Resampling Procedure}

The specifics of the resampling procedure described in Section 4.1 are more fully described below. Let $l \in[1,2, \ldots, L]$ denote the set of all auctions, and let $n_{l}$ be the number of bidders in a specific auction $l$.

- 1. Fix an auction ( $\operatorname{say} l$ ), and a bidder (say $i$ ). Find $n_{l}$.

- 2. Draw, with replacement, and appropriately weighted, $\left(n_{l}-1\right)$ actual submitted bid schedules from amongst all the schedules submitted across all the L auctions.

- 3. Aggregate these bids together, and use them to construct a residual supply function for bidder i.

\footnotetext{
${ }^{36}$ Since $y($.$) is strictly monotonic by assumption, this inverse is uniquely defined.$
} 
- 4. Intersect the simulated residual-supply function with bidder $i$ 's actual submitted demand schedule, and record the equilibrium stop-out price.

- 5. Repeat steps 2 to 4 B times to generate a sample of B simulated stop-out prices.

- 6. Use the simulated stop-out prices to generate a histogram and a 'cumulative histogram' - this generates $\mathrm{H}$.

For consistency of the bootstrap, Hortacsu and McAdams (2010) require the individual signals to be IID, conditional on the auction-specific covariates; this is a similar assumption to that used by Fevrier et al. (2002). The weighting terms used in re-sampling the bidding functions in Step 2. of the procedure are also analogous to the weighting terms Fevrier et al. (2002) use in generating their G-distribution.

The basic version of this resampling procedure gives all $n_{l}$ bid functions in each auction $l$ an equal weight, which will not reflect any asymmetries between the bidders, should they exist. Hortacsu and McAdams show, however, that consistency proof for the bootstrap can be modified to account for asymmetries. Instead of indiscriminately drawing $\left(n_{l}-1\right)$ bidding functions, the set of bidders can be subdivided into groups (e.g. according to size), so that there is less asymmetry within each group, and consequently the appropriate number of bidders from each group is drawn. This ensures that proportions of bidders from each group is the same as in the actual auction. In practice, when I estimate the $\mathrm{H}$-function using the asymmetry-adjusted resampling procedure, the results are almost identical to the base model.

\section{References}

[1] Armantier, O. and E. Sbai, "Estimation and comparison of treasury auction formats when bidders are asymmetric," Journal of Applied Econometrics, 2006, 21 (6), 745-779.

[2] Ausubel, L. M. and P. Cramton, "Demand Reduction and Inefficiency in MultiUnit Auctions," working paper, University of Maryland, 2002.

[3] _ _ _ _ M. Pycia, M. Rostek, and M. Weretka, "Demand Reduction, Inefficiency and Revenues in Multi-Unit Auctions," Review of Economic Studies, 2014, Forthcoming.

[4] Back, K. and J.F. Zender, "Auctions of divisible goods with endogenous supply," Economics Letters, 2001, 73 (1), 29-34.

[5] Efron, B. and RJ Tibshirani, An Introduction to the Bootstrap, Chapman and Hall/CRC, Boca Raton, 1998. 
[6] Fevrier, P., R. Preget, and M. Visser, "Econometrics of Share Auctions," mimeograph, University of Chicago and INRA, 2002.

[7] _ _ _ , and _ _ "Econometrics of Share Auctions," mimeograph, University of Chicago and INRA, 2004.

[8] Hortaçsu, A., "Mechanism Choice and Strategic Bidding in Divisible Good Auctions: An Empirical Analysis of the Turkish Treasury Auction Market," Typescript, Department of Economics, University of Chicago, 2002.

[9] Hortacsu, A. and J. Kastl, "Testing for Common Valuation in the Presence of Bidders with Informational Advantage," working paper presented at the Penn State auctions conference, April 2008, 2008.

[10] Kang, B. and S.L. Puller, "The Effect of Auction Format on Efficiency and Revenue In Divisible Goods Auctions: A Test Using Korean Treasury Auctions," The Journal of Industrial Economics, 2008, 56 (2), 0022-1821.

[11] Kastl, J., "Discrete bids and empirical inference in divisible good auctions," The Review of Economic Studies, 2011, 78 (3), 974-1014.

[12] Krawczyk, M., "Estimating Demand in Treasury Auctions: A Normal Cumulative Distribution Function Approach," working paper, CREED, University of Amsterdam, 2006.

[13] Marszalec, D., "Essays on Auctions," D.Phil Thesis, University of Oxford, 2011.

[14] Newey, W. K. and D. McFadden, "Large sample estimation and hypothesis testing," in R. F. Engle and D. McFadden, eds., Handbook of Econometrics, 1986.

[15] Pagan, A. and A. Ullah, Nonparametric Econometrics, Cambridge University Press, 1999.

[16] Ryu, K., G.R. Kim, and S. Oh, "Discriminatory vs Uniform Price Auction: Auction Revenue Comparison in the Case of the Korean Treasury Auction Market," Econometric Society 2004 Far Eastern Meetings, August 2004, (539).

[17] Wilson, R., "Auctions of Shares," The Quarterly Journal of Economics, November 1979, $93(4), 675-89$.

[18] Zender, J. F. and J.D. Wang, "research articles : Auctioning divisible goods," Economic Theory, 2002, 19 (4), 673-705. 


\section{Online Appendix A - Full Summary of Results from the HMA Model}

This section contains the full auction-level results from the HMA model.

Table 11: Auction-level Results from the HMA Model, 52-week Treasury Bills (1/3)

\begin{tabular}{cccc}
\hline \hline Auction & $\begin{array}{c}\text { Ex-Post Revenue } \\
\text { Number }\end{array}$ & $\begin{array}{c}\text { Ex-Ante Revenue Diff. } \\
\text { Liffence Low Bound }\end{array}$ & $\begin{array}{c}\text { Ex-Ante Revenue Diff. } \\
\text { High Bound }\end{array}$ \\
\hline 1 & $0.1273[0.0703,0.2048]$ & $0.0346[0.0346,0.0346]$ & $0.0352[0.0352,0.0352]$ \\
2 & $0.0341[0.0176,0.0684]$ & $0.0283[0.0283,0.0283]$ & $0.0288[0.0288,0.0288]$ \\
3 & $0.0399[0.0206,0.0762]$ & $0.0180[0.0180,0.0180]$ & $0.0185[0.0185,0.0185]$ \\
4 & $0.0129[-0.0005,0.0221]$ & $0.0070[0.0070,0.0070]$ & $0.0075[0.0075,0.0075]$ \\
5 & $0.0327[0.0211,0.0497]$ & $0.0200[0.0200,0.0200]$ & $0.0206[0.0206,0.0206]$ \\
6 & $0.0194[0.0114,0.0345]$ & $0.0106[0.0106,0.0106]$ & $0.0112[0.0112,0.0112]$ \\
7 & $0.0400[0.0221,0.0697]$ & $0.0179[0.0179,0.0179]$ & $0.0184[0.0184,0.0184]$ \\
8 & $0.0319[0.0140,0.0589]$ & $0.0127[0.0127,0.0127]$ & $0.0132[0.0132,0.0132]$ \\
9 & $0.0439[0.0313,0.0622]$ & $0.0293[0.0293,0.0293]$ & $0.0298[0.0298,0.0298]$ \\
10 & $0.0306[0.0161,0.0437]$ & $0.0141[0.0141,0.0141]$ & $0.0146[0.0146,0.0146]$ \\
11 & $0.0170[0.0091,0.0278]$ & $0.0057[0.0057,0.0057]$ & $0.0063[0.0063,0.0063]$ \\
12 & $0.0198[0.0086,0.0320]$ & $0.0139[0.0139,0.0139]$ & $0.0145[0.0145,0.0145]$ \\
13 & $0.0397[0.0167,0.2053]$ & $0.0112[0.0112,0.0112]$ & $0.0118[0.0118,0.0118]$ \\
14 & $0.0357[0.0097,0.1370]$ & $0.0012[0.0012,0.0012]$ & $0.0017[0.0017,0.0017]$ \\
15 & $0.0230[0.0131,0.0364]$ & $0.0108[0.0108,0.0108]$ & $0.0113[0.0113,0.0113]$ \\
16 & $0.0255[0.0137,0.0447]$ & $0.0184[0.0184,0.0184]$ & $0.0189[0.0189,0.0189]$ \\
17 & $0.0172[0.0064,0.0291]$ & $0.0086[0.0086,0.0086]$ & $0.0091[0.0091,0.0091]$ \\
18 & $0.0171[0.0077,0.0329]$ & $0.0022[0.0022,0.0022]$ & $0.0028[0.0028,0.0028]$ \\
19 & $0.0493[0.0002,0.1326]$ & $0.0398[0.0398,0.0398]$ & $0.0404[0.0404,0.0404]$ \\
20 & $0.0157[0.0044,0.0378]$ & $0.0083[0.0083,0.0083]$ & $0.0088[0.0088,0.0088]$ \\
21 & $0.0138[0.0077,0.0223]$ & $0.0089[0.0089,0.0089]$ & $0.0094[0.0094,0.0094]$ \\
22 & $0.0151[0.0087,0.0218]$ & $0.0080[0.0080,0.0080]$ & $0.0085[0.0085,0.0085]$ \\
23 & $0.0107[0.0025,0.0170]$ & $0.0123[0.0123,0.0123]$ & $0.0128[0.0128,0.0128]$ \\
24 & $0.0148[0.0073,0.0203]$ & $0.0078[0.0078,0.0078]$ & $0.0084[0.0084,0.0084]$ \\
25 & $0.0125[0.0059,0.0198]$ & $0.0059[0.0059,0.0059]$ & $0.0064[0.0064,0.0064]$ \\
26 & $0.0151[0.0049,0.0277]$ & $0.0152[0.0152,0.0152]$ & $0.0157[0.0157,0.0157]$ \\
27 & $0.0158[0.0102,0.0232]$ & $0.0109[0.0109,0.0109]$ & $0.0114[0.0114,0.0114]$ \\
28 & $0.0151[0.0050,0.0216]$ & $0.0061[0.0061,0.0061]$ & $0.0067[0.0067,0.0067]$ \\
29 & $0.0048[-0.0004,0.0172]$ & $0.0013[0.0013,0.0013]$ & $0.0018[0.0018,0.0018]$ \\
\hline & & & \\
\hline
\end{tabular}


Table 12: Auction-level Results from the HMA Model, 52-week Treasury Bills (2/3)

\begin{tabular}{|c|c|c|c|}
\hline $\begin{array}{l}\text { Auction } \\
\text { Number }\end{array}$ & $\begin{array}{c}\text { Ex-Post Revenue } \\
\text { Difference Low Bound }\end{array}$ & $\begin{array}{l}\text { Ex-Ante Revenue Diff. } \\
\text { Low Bound }\end{array}$ & $\begin{array}{c}\text { Ex-Ante Revenue Diff. } \\
\text { High Bound }\end{array}$ \\
\hline 30 & $0.0074[-0.0005,0.0217]$ & $0.0077[0.0077,0.0077]$ & $0.0082[0.0082,0.0082]$ \\
\hline 31 & $0.0086[0.0013,0.0175]$ & $0.0039[0.0039,0.0039]$ & $0.0045[0.0045,0.0045]$ \\
\hline 32 & $0.0247[-0.0005,0.0622]$ & $0.0241[0.0241,0.0241]$ & $0.0247[0.0247,0.0247]$ \\
\hline 33 & $0.0116[0.0004,0.0207]$ & $0.0032[0.0032,0.0032]$ & $0.0037[0.0037,0.0037]$ \\
\hline 34 & $0.0137[0.0041,0.0236]$ & $0.0046[0.0046,0.0046]$ & $0.0051[0.0051,0.0051]$ \\
\hline 35 & $0.0190[0.0061,0.0333]$ & $0.0200[0.0200,0.0200]$ & $0.0205[0.0205,0.0205]$ \\
\hline 36 & $0.0083[0.0020,0.0178]$ & $0.0061[0.0061,0.0061]$ & $0.0066[0.0066,0.0066]$ \\
\hline 37 & $0.0103[0.0047,0.0204]$ & $0.0066[0.0066,0.0066]$ & $0.0072[0.0072,0.0072]$ \\
\hline 38 & $0.0063[-0.0004,0.0324]$ & $-0.0001[-0.0001,-0.0001]$ & $0.0005[0.0005,0.0005]$ \\
\hline 39 & $0.0359[0.0229,0.0512]$ & $0.0129[0.0129,0.0129]$ & $0.0134[0.0134,0.0134]$ \\
\hline 40 & $0.0076[-0.0002,0.0223]$ & $0.0014[0.0014,0.0014]$ & $0.0019[0.0019,0.0019]$ \\
\hline 41 & $0.0123[0.0001,0.0498]$ & $0.0001[0.0001,0.0001]$ & $0.0006[0.0006,0.0006]$ \\
\hline 42 & $0.0200[0.0130,0.0295]$ & $0.0100[0.0100,0.0100]$ & $0.0106[0.0106,0.0106]$ \\
\hline 43 & $0.0200[0.0065,0.0404]$ & $0.0127[0.0127,0.0127]$ & $0.0132[0.0132,0.0132]$ \\
\hline 44 & $0.0347[0.0152,0.1241]$ & $0.0147[0.0147,0.0147]$ & $0.0152[0.0152,0.0152]$ \\
\hline 45 & $0.0308[0.0010,0.0762]$ & $0.0044[0.0044,0.0044]$ & $0.0049[0.0049,0.0049]$ \\
\hline 46 & $0.0123[-0.0004,0.0364]$ & $0.0047[0.0047,0.0047]$ & $0.0053[0.0053,0.0053]$ \\
\hline 47 & $0.0181[0.0093,0.0385]$ & $0.0156[0.0156,0.0156]$ & $0.0162[0.0162,0.0162]$ \\
\hline 48 & $0.0149[0.0055,0.0264]$ & $0.0081[0.0081,0.0081]$ & $0.0087[0.0087,0.0087]$ \\
\hline 49 & $0.0151[0.0010,0.0325]$ & $0.0030[0.0030,0.0030]$ & $0.0035[0.0035,0.0035]$ \\
\hline 50 & $0.0179[0.0072,0.0462]$ & $0.0111[0.0111,0.0111]$ & $0.0116[0.0116,0.0116]$ \\
\hline 51 & $0.0180[0.0078,0.0301]$ & $0.0132[0.0132,0.0132]$ & $0.0137[0.0137,0.0137]$ \\
\hline 52 & $0.0177[0.0042,0.0336]$ & $0.0028[0.0028,0.0028]$ & $0.0034[0.0034,0.0034]$ \\
\hline 53 & $0.0238[0.0028,0.0470]$ & $0.0213[0.0213,0.0213]$ & $0.0218[0.0218,0.0218]$ \\
\hline 54 & $0.0301[0.0054,0.0732]$ & $0.0066[0.0066,0.0066]$ & $0.0072[0.0072,0.0072]$ \\
\hline 55 & $0.0190[0.0011,0.0416]$ & $0.0093[0.0093,0.0093]$ & $0.0098[0.0098,0.0098]$ \\
\hline 56 & $0.0124[0.0026,0.0253]$ & $0.0064[0.0064,0.0064]$ & $0.0069[0.0069,0.0069]$ \\
\hline 57 & $0.0109[0.0037,0.0241]$ & $0.0060[0.0060,0.0060]$ & $0.0065[0.0065,0.0065]$ \\
\hline 58 & $0.0117[-0.0005,0.0254]$ & $0.0080[0.0080,0.0080]$ & $0.0085[0.0085,0.0085]$ \\
\hline 59 & $0.0013[-0.0005,0.0156]$ & $-0.0002[-0.0002,-0.0002]$ & $0.0003[0.0003,0.0003]$ \\
\hline 60 & $0.0412[0.0218,0.1475]$ & $0.0152[0.0152,0.0152]$ & $0.0157[0.0157,0.0157]$ \\
\hline 61 & $0.0303[0.0086,0.0526]$ & $0.0275[0.0275,0.0275]$ & $0.0280[0.0280,0.0280]$ \\
\hline 62 & $0.0197[0.0018,0.0338]$ & $0.0111[0.0111,0.0111]$ & $0.0116[0.0116,0.0116]$ \\
\hline 63 & $0.0147[0.0081,0.0230]$ & $0.0104[0.0104,0.0104]$ & $0.0109[0.0109,0.0109]$ \\
\hline 64 & $0.0304[0.0172,0.0470]$ & $0.0237[0.0237,0.0237]$ & $0.0242[0.0242,0.0242]$ \\
\hline 65 & $0.0225[0.0140,0.0325]$ & $0.0112[0.0112,0.0112]$ & $0.0117[0.0117,0.0117]$ \\
\hline 66 & $0.0307[0.0178,0.0514]$ & $0.0263[0.0263,0.0263]$ & $0.0268[0.0268,0.0268]$ \\
\hline 67 & $0.0203[0.0089,0.0341]$ & $0.0130[0.0130,0.0130]$ & $0.0135[0.0135,0.0135]$ \\
\hline 68 & $0.0511[0.0275,0.0921]$ & $0.0106[0.0106,0.0106]$ & $0.0111[0.0111,0.0111]$ \\
\hline 69 & $0.0415[-0.0005,0.0908]$ & $0.0445[0.0445,0.0445]$ & $0.0451[0.0451,0.0451]$ \\
\hline 70 & $0.0187[0.0103,0.0331]$ & $0.0123[0.0123,0.0123]$ & $0.0128[0.0128,0.0128]$ \\
\hline 71 & $0.0198[0.0097,0.0344]$ & $0.0126[0.0126,0.0126]$ & $0.0131[0.0131,0.0131]$ \\
\hline 72 & $0.0084[0.0006,0.0249]$ & $0.0060[0.0060,0.0060]$ & $0.0065[0.0065,0.0065]$ \\
\hline 73 & $0.0063[-0.0004,0.0169]$ & $0.0009[0.0009,0.0009]$ & $0.0014[0.0014,0.0014]$ \\
\hline
\end{tabular}


Table 13: Auction-level Results from the HMA Model, 52-week Treasury Bills (3/3)

\begin{tabular}{|c|c|c|c|}
\hline $\begin{array}{l}\text { Auction } \\
\text { Number }\end{array}$ & $\begin{array}{c}\text { Ex-Post Revenue } \\
\text { Difference Low Bound }\end{array}$ & $\begin{array}{l}\text { Ex-Ante Revenue Diff. } \\
\text { Low Bound }\end{array}$ & $\begin{array}{c}\text { Ex-Ante Revenue Diff. } \\
\text { High Bound }\end{array}$ \\
\hline 74 & $0.0437[0.0198,0.0872]$ & $0.0152[0.0152,0.0152]$ & $0.0157[0.0157,0.0157]$ \\
\hline 75 & $0.0305[0.0166,0.0521]$ & $0.0120[0.0120,0.0120]$ & $0.0125[0.0125,0.0125]$ \\
\hline 76 & $0167[0.0059,0.0291]$ & $0.0112[0.0112,0.0112]$ & $0.0117[0.0117,0.0117]$ \\
\hline 77 & $0148[0.0090,0.0206]$ & $0.0102[0.0102,0.0102]$ & $0.0107[0.0107,0.0107]$ \\
\hline 78 & $0148[0.0062,0.0280]$ & $0.0077[0.0077,0.0077]$ & $0.0082[0.0082,0.0082]$ \\
\hline 79 & $0268[0.0103,0.0694]$ & $0.0051[0.0051,0.0051]$ & $0.0057[0.0057,0.0057]$ \\
\hline 80 & $0115[0.0068,0.0267]$ & $0.0023[0.0023,0.0023]$ & $0.0029[0.0029,0.0029]$ \\
\hline 81 & $.0521[0.0192,0.1120]$ & $0.0058[0.0058,0.0058]$ & $0.0063[0.0063,0.0063]$ \\
\hline 82 & $0382[0.0209,0.0$ & $0.0165[0.0165,0.0165]$ & $170,0.0170$ \\
\hline 83 & $0332[0.0164,0.0699]$ & $0.0059[0.0059,0.0059]$ & $0.0065[0.0065,0.0065]$ \\
\hline 84 & $101[0.0$ & $0.0031[0.0031,0.0031]$ & $0.0036[0.0036,0.0036]$ \\
\hline 85 & $0190[0.0045,0.0369]$ & $0.0040[0.0040,0.0040]$ & $0.0045[0.0045,0.0045]$ \\
\hline 86 & $0134[0.0078,0.0$ & $0.0067[0.0067,0.0067]$ & $0.0072[0$. \\
\hline 87 & $107[0.0037,0.0$ & $0.0029[0.0029,0.0029]$ & $034,0.0034]$ \\
\hline 88 & $0149[0.0044,0.0$ & $0.0079[0.0079,0.0079]$ & $0.0084[0.1$ \\
\hline 89 & $0174[0.0115,0.0$ & $0.0157[0.0157,0.0157]$ & $0.0162[0.0162,0.0162]$ \\
\hline 90 & $111[0.0054,0.0$ & $0.0066[0.0066,0.0066]$ & $0.0072[0.0072,0.0072]$ \\
\hline 91 & $0.0198[0.0046,0.0568]$ & $0.0060[0.0060,0.0060]$ & $0.0066[0.0066,0.0066]$ \\
\hline 92 & $0.0380[0.0185,0.0478]$ & $0.0195[0.0195,0.0195]$ & $0.0200[0.0200,0.0200]$ \\
\hline 93 & $0.0090[0.0006,0.0$ & $0.0053[0.0053,0.00$ & $058,0.0058]$ \\
\hline 94 & $.0097[0.0059,0.0]$ & $0.0059[0.0059,0.0059]$ & $0.0064[0.0064,0.0064]$ \\
\hline 95 & $1583[0.0047,1.0322]$ & $0.0084[0.0084,0.0084]$ & $0.0089[0.0089,0.0089]$ \\
\hline 96 & $0.0363[0.0123,0.2477]$ & $0.0079[0.0079,0.0079]$ & $0.0084[0.0084,0.0084]$ \\
\hline 97 & $0239[-0.0005,0.2107]$ & $0.0189[0.0189,0.0189]$ & $0.0194[0.0194,0.0194]$ \\
\hline 98 & $0503[0.0254,0.0$ & $193,0.0196$ & $199,0.0201]$ \\
\hline 99 & $344[0.0119,0.1$ & $0.0083[0.0083,0.0083]$ & $0.0088[0.0088,0.0088]$ \\
\hline 100 & $0.0336[0.0201,0.0829]$ & $0.0166[0.0166,0.0166]$ & $0.0171[0.0171,0.0171]$ \\
\hline & $0.0439[0.0228,0.1139]$ & $0.0054[0.0054,0.0054]$ & $0.0059[0.0059,0.0059]$ \\
\hline & $0.0200[0.0117,0.0526]$ & $0.0078[0.0078,0.0078]$ & $0.0083[0.0083,0.0083]$ \\
\hline 103 & $0.0101[-0.0000,0.0287]$ & $0.0185[0.0185,0.0185]$ & $0.0190[0.0190,0.0190]$ \\
\hline
\end{tabular}


Table 14: Auction-level Results from the HMA Model, 2-year Bonds

\begin{tabular}{|c|c|c|c|}
\hline $\begin{array}{l}\text { Auction } \\
\text { Number }\end{array}$ & $\begin{array}{c}\text { Ex-Post Revenue } \\
\text { Difference Low Bound }\end{array}$ & $\begin{array}{c}\text { Ex-Ante Revenue Diff. } \\
\text { Low Bound }\end{array}$ & $\begin{array}{c}\text { Ex-Ante Revenue Diff. } \\
\text { High Bound }\end{array}$ \\
\hline 1 & $0.0267[0.0116,0.0427]$ & $0.0102[0.0102,0.0102]$ & $0.0108[0.0108,0.0108]$ \\
\hline 2 & $0.1747[0.0534,0.5387]$ & $0.0209[0.0209,0.0209]$ & $0.0214[0.0214,0.0214]$ \\
\hline 3 & $0.1081[-0.0004,0.6683]$ & $0.0072[0.0072,0.0072]$ & $0.0077[0.0077,0.0077]$ \\
\hline 4 & $0.4480[0.1301,1.0588]$ & $0.1438[0.1438,0.1438]$ & $0.1443[0.1443,0.1443]$ \\
\hline 5 & $0.0474[0.0202,0.0739]$ & $0.0181[0.0181,0.0181]$ & $0.0186[0.0186,0.0186]$ \\
\hline 6 & $0.0537[0.0332,0.1087]$ & $0.0178[0.0178,0.0178]$ & $0.0184[0.0184,0.0184]$ \\
\hline 7 & $0.0746[0.0069,0.2185]$ & $0.0251[0.0251,0.0251]$ & $0.0256[0.0256,0.0256]$ \\
\hline 8 & $0.0458[0.0253,0.0809]$ & $0.0207[0.0207,0.0207]$ & $0.0213[0.0213,0.0213]$ \\
\hline 9 & $0.2678[0.0801,0.5780]$ & $0.0916[0.0916,0.0916]$ & $0.0922[0.0922,0.0922]$ \\
\hline 10 & $0.1016[0.0493,0.1585]$ & $0.0312[0.0312,0.0312]$ & $0.0318[0.0318,0.0318]$ \\
\hline 11 & $0.0503[0.0302,0.0$ & $0.0279[0.0279,0.0279]$ & $0.0285[0.0285,0.0285]$ \\
\hline 12 & $0.0494[0.0196,0.0851]$ & $0.0158[0.0158,0.0158]$ & $0.0163[0.0163,0.0163]$ \\
\hline 13 & $0.1394[0.0689,0.5047]$ & $0.0340[0.0340,0.0340]$ & $0.0346[0.0346,0.0346]$ \\
\hline 14 & $0.0379[0.0101,0.0953]$ & $0.0160[0.0160,0.0160]$ & $0.0165[0.0165,0.0165]$ \\
\hline 15 & $0.0518[0.0157,0.1331]$ & $0.0128[0.0128,0.0128]$ & $0.0134[0.0134,0.0134]$ \\
\hline 16 & $0.0263[0.0027,0.0667]$ & $0.0014[0.0014,0.0014]$ & $0.0019[0.0019,0.0019]$ \\
\hline 17 & $0.0483[0.0315,0.0669]$ & $0.0230[0.0230,0.0230]$ & $0.0236[0.0236,0.0236]$ \\
\hline 18 & $0.0170[0.0006,0.0569]$ & $0.0039[0.0039,0.0039]$ & $0.0045[0.0045,0.0045]$ \\
\hline 19 & $0.0991[0.0445,0.1686]$ & $0.0437[0.0437,0.0437]$ & $0.0442[0.0442,0.0442]$ \\
\hline 20 & $0.0410[0.0191,0.0683]$ & $0.0152[0.0152,0.0152]$ & $0.0158[0.0158,0.0158]$ \\
\hline 21 & $0.0622[0.0092,0.1273]$ & $0.0145[0.0145,0.0145]$ & $0.0151[0.0151,0.0151]$ \\
\hline 22 & $0.0509[0.0241,0.0800]$ & $0.0199[0.0199,0.0199]$ & $0.0205[0.0205,0.0205]$ \\
\hline 23 & $0.1048[0.0570,0.1910]$ & $0.0452[0.0452,0.0452]$ & $0.0457[0.0457,0.0457]$ \\
\hline 24 & $0.0395[0.0271,0.0579]$ & $0.0147[0.0147,0.0147]$ & $0.0153[0.0153,0.0153]$ \\
\hline 25 & $0.0507[0.0320,0.0742]$ & $0.0176[0.0176,0.0176]$ & $0.0181[0.0181,0.0181]$ \\
\hline 26 & $0.0489[0.0265,0.0752]$ & $0.0278[0.0278,0.0278]$ & $0.0284[0.0284,0.0284]$ \\
\hline 27 & $0.0567[0.0305,0.1127]$ & $0.0248[0.0248,0.0248]$ & $0.0254[0.0254,0.0254]$ \\
\hline 28 & $0.0225[0.0104,0.0454]$ & $0.0182[0.0182,0.0182]$ & $0.0188[0.0188,0.0188]$ \\
\hline 29 & $0.0222[0.0114,0.0482]$ & $0.0112[0.0112,0.0112]$ & $0.0118[0.0118,0.0118]$ \\
\hline 30 & $0.0488[0.0266,0.0844]$ & $0.0213[0.0213,0.0213]$ & $0.0219[0.0219,0.0219]$ \\
\hline 31 & $0.0282[0.0171,0.0541]$ & $0.0177[0.0177,0.0177]$ & $0.0182[0.0182,0.0182]$ \\
\hline 32 & $0.0235[0.0152,0.0402]$ & $0.0165[0.0165,0.0165]$ & $0.0171[0.0171,0.0171]$ \\
\hline 33 & $0.0286[0.0114,0.0492]$ & $0.0189[0.0189,0.0189]$ & $0.0194[0.0194,0.0194]$ \\
\hline 34 & $0.0424[0.0218,0.1005]$ & $0.0153[0.0153,0.0153]$ & $0.0159[0.0159,0.0159]$ \\
\hline 35 & $0.0307[0.0135,0.0457]$ & $0.0149[0.0149,0.0149]$ & $0.0154[0.0154,0.0154]$ \\
\hline 36 & $0.0441[0.0225,0.0747]$ & $0.0218[0.0218,0.0218]$ & $0.0224[0.0224,0.0224]$ \\
\hline 37 & $0.0161[0.0079,0.0275]$ & $0.0116[0.0116,0.0116]$ & $0.0122[0.0122,0.0122]$ \\
\hline 38 & $0.0372[0.0137,0.0711]$ & $0.0280[0.0280,0.0280]$ & $0.0286[0.0286,0.0286]$ \\
\hline 39 & $0.0191[0.0111,0.0292]$ & $0.0123[0.0123,0.0123]$ & $0.0129[0.0129,0.0129]$ \\
\hline 40 & $0.0328[0.0140,0.0500]$ & $0.0164[0.0164,0.0164]$ & $0.0169[0.0169,0.0169]$ \\
\hline 41 & $0.0233[0.0090,0.0472]$ & $0.0102[0.0102,0.0102]$ & $0.0108[0.0108,0.0108]$ \\
\hline 42 & $0.0244[0.0083,0.0433]$ & $0.0128[0.0128,0.0128]$ & $0.0133[0.0133,0.0133]$ \\
\hline
\end{tabular}




\section{Online Appendix B - Full Summary of Results from the FPV Model}

This section contains the full auction-level results from the FPV model.

Table 15: Auction-level Results from the FPV Model, 52-week Treasury Bills (/3)

\begin{tabular}{cccccc}
\hline \hline $\begin{array}{c}\text { Auction } \\
\text { Number }\end{array}$ & $\begin{array}{c}\text { Common } \\
\text { Value }\end{array}$ & $\begin{array}{c}\text { Ex-Post } \\
\text { DP Revenue }\end{array}$ & $\begin{array}{c}\text { Ex-Post } \\
\text { UP Revenue }\end{array}$ & $\begin{array}{c}\text { Ex-Post Revenue } \\
\text { Difference }(\%)\end{array}$ & $\begin{array}{c}\text { Ex-Ante Revenue } \\
\text { Difference }(\%)\end{array}$ \\
\hline 1 & 93.72 & 93.58 & 93.37 & 0.23 & $0.17[0.00,0.25]$ \\
2 & 93.74 & 93.43 & 93.39 & 0.04 & $0.04[0.01,0.05]$ \\
3 & 93.72 & 93.46 & 93.37 & 0.10 & $0.09[0.08,0.11]$ \\
4 & 93.80 & 93.51 & 93.45 & 0.07 & $0.06[0.04,0.08]$ \\
5 & 93.95 & 93.57 & 93.60 & -0.02 & $-0.03[-0.04,-0.01]$ \\
6 & 93.90 & 93.58 & 93.55 & 0.03 & $0.03[0.02,0.05]$ \\
7 & 93.85 & 93.51 & 93.49 & 0.02 & $0.02[-0.00,0.00]$ \\
8 & 93.59 & 93.40 & 93.24 & 0.18 & $0.17[0.07,0.26]$ \\
9 & 93.39 & 93.22 & 93.03 & 0.21 & $0.20[0.15,0.24]$ \\
10 & 93.26 & 93.13 & 92.90 & 0.25 & $0.24[0.17,0.30]$ \\
11 & 93.32 & 93.18 & 92.95 & 0.24 & $0.24[0.17,0.28]$ \\
12 & 93.27 & 93.20 & 92.90 & 0.32 & $0.32[0.26,0.36]$ \\
13 & 93.28 & 93.19 & 92.91 & 0.31 & $0.28[0.00,0.33]$ \\
14 & 93.14 & 93.16 & 92.77 & 0.42 & $0.38[0.00,0.50]$ \\
15 & 93.45 & 93.22 & 93.08 & 0.16 & $0.16[0.12,0.19]$ \\
16 & 93.01 & 92.99 & 92.62 & 0.39 & $0.39[0.30,0.46]$ \\
17 & 92.90 & 92.96 & 92.51 & 0.48 & $0.48[0.39,0.56]$ \\
18 & 92.78 & 92.95 & 92.39 & 0.59 & $0.59[0.46,0.68]$ \\
19 & 93.09 & 93.11 & 92.71 & 0.44 & $0.43[0.36,0.53]$ \\
20 & 93.15 & 93.09 & 92.77 & 0.35 & $0.34[0.28,0.38]$ \\
21 & 93.56 & 93.32 & 93.19 & 0.14 & $0.14[0.10,0.16]$ \\
22 & 93.53 & 93.33 & 93.17 & 0.17 & $0.17[0.15,0.19]$ \\
23 & 93.63 & 93.38 & 93.27 & 0.12 & $0.12[0.09,0.14]$ \\
24 & 93.68 & 93.42 & 93.32 & 0.10 & $0.10[0.08,0.12]$ \\
25 & 93.75 & 93.44 & 93.40 & 0.05 & $0.05[0.03,0.07]$ \\
26 & 93.81 & 93.49 & 93.46 & 0.03 & $0.03[0.01,0.05]$ \\
27 & 93.98 & 93.59 & 93.63 & -0.04 & $-0.04[-0.06,-0.03]$ \\
28 & 93.90 & 93.61 & 93.55 & 0.07 & $0.07[0.06,0.08]$ \\
29 & 93.81 & 93.66 & 93.46 & 0.21 & $0.20[0.16,0.22]$ \\
\hline & & & &
\end{tabular}


Table 16: Auction-level Results from the FPV Model, 52-week Treasury Bills (2/3)

\begin{tabular}{|c|c|c|c|c|c|}
\hline $\begin{array}{l}\text { Auction } \\
\text { Number }\end{array}$ & $\begin{array}{l}\text { Common } \\
\text { Value }\end{array}$ & $\begin{array}{c}\text { Ex-Post } \\
\text { DP Revenue }\end{array}$ & $\begin{array}{c}\text { Ex-Post } \\
\text { UP Revenue }\end{array}$ & $\begin{array}{c}\text { Ex-Post Revenue } \\
\text { Difference }(\%)\end{array}$ & $\begin{array}{c}\text { Ex-Ante Revenue } \\
\text { Difference }(\%)\end{array}$ \\
\hline 30 & 94.05 & 93.80 & 93.71 & 0.09 & $0.09[0.04,0.12]$ \\
\hline 31 & 94.13 & 93.87 & 93.79 & 0.08 & $0.08[0.05,0.09]$ \\
\hline 32 & 94.23 & 93.95 & 93.90 & 0.06 & $0.05[0.00,0.10]$ \\
\hline 33 & 94.43 & 94.06 & 94.10 & -0.05 & $-0.05[-0.07,-0.05]$ \\
\hline 34 & 94.46 & 94.05 & 94.13 & -0.09 & $-0.09[-0.10,-0.08]$ \\
\hline 35 & 94.38 & 93.98 & 94.05 & -0.07 & $-0.07[-0.08,-0.06]$ \\
\hline 36 & 94.40 & 94.02 & 94.07 & -0.05 & $-0.05[-0.06,-0.04]$ \\
\hline 37 & 94.37 & 94.06 & 94.04 & 0.03 & $0.03[0.01,0.04]$ \\
\hline 38 & 94.47 & 94.21 & 94.14 & 0.07 & $0.06[0.04,0.08]$ \\
\hline 39 & 94.48 & 94.23 & 94.16 & 0.08 & $0.08[0.02,0.13]$ \\
\hline 40 & 94.70 & 94.42 & 94.38 & 0.04 & $0.03[0.01,0.05]$ \\
\hline 41 & 94.98 & 94.71 & 94.68 & 0.03 & $0.01[-0.04,0.00]$ \\
\hline 42 & 94.91 & 94.68 & 94.60 & 0.08 & $0.08[0.06,0.10]$ \\
\hline 43 & 95.00 & 94.74 & 94.70 & 0.05 & $0.04[0.02,0.06]$ \\
\hline 44 & 95.04 & 94.77 & 94.74 & 0.03 & $0.03[0.00,0.05]$ \\
\hline 45 & 94.95 & 94.73 & 94.65 & 0.08 & $0.08[0.03,0.11]$ \\
\hline 46 & 95.03 & 94.83 & 94.73 & 0.11 & $0.11[0.08,0.12]$ \\
\hline 47 & 95.13 & 94.85 & 94.83 & 0.02 & $0.02[-0.00,0.00]$ \\
\hline 48 & 95.16 & 94.89 & 94.86 & 0.03 & $0.03[0.00,0.05]$ \\
\hline 49 & 95.24 & 94.98 & 94.95 & 0.03 & $0.03[0.00,0.04]$ \\
\hline 50 & 95.27 & 95.06 & 94.97 & 0.09 & $0.09[0.07,0.10]$ \\
\hline 51 & 95.34 & 95.11 & 95.05 & 0.06 & $0.05[0.04,0.06]$ \\
\hline 52 & 95.36 & 95.10 & 95.07 & 0.03 & $0.03[0.01,0.04]$ \\
\hline 53 & 95.51 & 95.27 & 95.23 & 0.05 & $0.04[0.03,0.06]$ \\
\hline 54 & 95.54 & 95.32 & 95.26 & 0.07 & $0.07[0.00,0.08]$ \\
\hline 55 & 95.68 & 95.46 & 95.40 & 0.07 & $0.06[0.01,0.08]$ \\
\hline 56 & 95.73 & 95.56 & 95.46 & 0.11 & $0.11[0.10,0.12]$ \\
\hline 57 & 95.97 & 95.80 & 95.71 & 0.09 & $0.09[0.07,0.10]$ \\
\hline 58 & 95.96 & 95.84 & 95.69 & 0.16 & $0.15[0.13,0.16]$ \\
\hline 59 & 96.27 & 95.95 & 96.01 & -0.07 & $-0.07[-0.10,-0.07]$ \\
\hline 60 & 96.01 & 95.81 & 95.75 & 0.07 & $0.07[0.00,0.08]$ \\
\hline 61 & 95.85 & 95.72 & 95.59 & 0.14 & $0.13[0.11,0.15]$ \\
\hline 62 & 96.08 & 95.92 & 95.82 & 0.11 & $0.10[0.09,0.11]$ \\
\hline 63 & 96.22 & 96.01 & 95.96 & 0.05 & $0.05[0.04,0.05]$ \\
\hline 64 & 96.16 & 95.97 & 95.90 & 0.08 & $0.08[0.06,0.09]$ \\
\hline 65 & 96.03 & 95.88 & 95.77 & 0.12 & $0.12[0.11,0.13]$ \\
\hline 66 & 95.79 & 95.73 & 95.53 & 0.21 & $0.21[0.18,0.23]$ \\
\hline 67 & 95.84 & 95.76 & 95.57 & 0.20 & $0.20[0.18,0.21]$ \\
\hline 68 & 95.92 & 95.68 & 95.65 & 0.02 & $0.02[-0.01,0.00]$ \\
\hline 69 & 95.90 & 95.81 & 95.63 & 0.19 & $0.17[0.10,0.22]$ \\
\hline 70 & 95.92 & 95.74 & 95.66 & 0.09 & $0.09[0.06,0.11]$ \\
\hline 71 & 96.00 & 95.91 & 95.74 & 0.18 & $0.18[0.16,0.18]$ \\
\hline 72 & 96.18 & 96.01 & 95.92 & 0.09 & $0.09[0.08,0.10]$ \\
\hline
\end{tabular}


Table 17: Auction-level Results from the FPV Model, 52-week Treasury Bills (3/3)

\begin{tabular}{|c|c|c|c|c|c|}
\hline $\begin{array}{l}\text { Auction } \\
\text { Number }\end{array}$ & $\begin{array}{l}\text { Common } \\
\text { Value }\end{array}$ & $\begin{array}{c}\text { Ex-Post } \\
\text { DP Revenue }\end{array}$ & $\begin{array}{c}\text { Ex-Post } \\
\text { UP Revenue }\end{array}$ & $\begin{array}{c}\text { Ex-Post Revenue } \\
\text { Difference }(\%)\end{array}$ & $\begin{array}{c}\text { Ex-Ante Revenue } \\
\text { Difference (\%) }\end{array}$ \\
\hline 73 & 96.41 & 96.23 & 96.16 & 0.07 & $0.07[0.06,0.08]$ \\
\hline 74 & 96.77 & 96.31 & 96.52 & -0.21 & $-0.22[-0.24,-0.20$ \\
\hline 75 & 96.57 & 96.18 & 96.32 & -0.14 & $-0.14[-0.16,-0.13$ \\
\hline 76 & 96.31 & 96.12 & 96.05 & 0.07 & $0.07[0.06,0.08]$ \\
\hline 77 & 96.43 & 96.14 & 96.18 & -0.04 & $-0.04[-0.05,-0.03]$ \\
\hline 78 & 96.37 & 96.12 & 96.11 & 0.01 & $0.01[-0.00,0.00]$ \\
\hline 79 & 96.26 & 96.05 & 96.00 & 0.06 & $0.05[0.03,0.07]$ \\
\hline 80 & 96.23 & 96.04 & 95.98 & 0.06 & $0.06[0.04,0.08]$ \\
\hline 81 & 96.10 & 95.92 & 95.84 & 0.09 & $0.06[0.00,0.10]$ \\
\hline 82 & 95.68 & 95.61 & 95.41 & 0.21 & $0.20[0.15,0.25]$ \\
\hline 83 & 95.86 & 95.82 & 95.60 & 0.23 & $0.22[0.18,0.26]$ \\
\hline 84 & 95.93 & 95.80 & 95.67 & 0.14 & $0.14[0.12,0.16]$ \\
\hline 85 & 95.74 & 95.73 & 95.47 & 0.27 & $0.27[0.22,0.30]$ \\
\hline 86 & 95.67 & 95.69 & 95.41 & 0.29 & $0.29[0.22,0.34]$ \\
\hline 87 & 95.66 & 95.71 & 95.39 & 0.33 & $0.32[0.28,0.35]$ \\
\hline 88 & 95.77 & 95.77 & 95.50 & 0.28 & $0.28[0.25,0.30]$ \\
\hline 89 & 95.90 & 95.80 & 95.64 & 0.16 & $0.16[0.14,0.18]$ \\
\hline 90 & 95.92 & 95.81 & 95.66 & 0.15 & $0.15[0.13,0.17]$ \\
\hline 91 & 95.99 & 95.87 & 95.73 & 0.15 & $0.14[0.12,0.15]$ \\
\hline 92 & 96.09 & 95.92 & 95.83 & 0.09 & $0.09[0.08,0.10]$ \\
\hline 93 & 96.09 & 95.92 & 95.83 & 0.09 & $0.09[0.08,0.09]$ \\
\hline 94 & 96.04 & 95.93 & 95.78 & 0.15 & $0.15[0.12,0.18]$ \\
\hline 95 & 96.22 & 96.03 & 95.97 & 0.07 & $0.06[0.00,0.07]$ \\
\hline 96 & 96.19 & 96.00 & 95.94 & 0.07 & $0.06[0.00,0.08]$ \\
\hline 97 & 96.13 & 96.02 & 95.88 & 0.15 & $0.13[0.09,0.15]$ \\
\hline 98 & 96.00 & 95.93 & 95.74 & 0.19 & $0.17[0.00,0.21]$ \\
\hline 99 & 95.96 & 95.87 & 95.70 & 0.17 & $0.17[0.00,0.19]$ \\
\hline 100 & 95.73 & 95.77 & 95.47 & 0.31 & $0.30[0.24,0.35]$ \\
\hline 101 & 95.62 & 95.72 & 95.36 & 0.38 & $0.34[0.00,0.44]$ \\
\hline 102 & 95.64 & 95.67 & 95.37 & 0.30 & $0.29[0.17,0.38]$ \\
\hline 103 & 95.58 & 95.76 & 95.32 & 0.46 & $0.46[0.41,0.49]$ \\
\hline
\end{tabular}


Table 18: Auction-level Results from the FPV Model, 2-year Bonds

\begin{tabular}{|c|c|c|c|c|c|}
\hline $\begin{array}{l}\text { Auction } \\
\text { Number }\end{array}$ & $\begin{array}{l}\text { Common } \\
\text { Value }\end{array}$ & $\begin{array}{c}\text { Ex-Post } \\
\text { DP Revenue }\end{array}$ & $\begin{array}{c}\text { Ex-Post } \\
\text { UP Revenue }\end{array}$ & $\begin{array}{c}\text { Ex-Post Revenue } \\
\text { Difference }(\%)\end{array}$ & $\begin{array}{c}\text { Ex-Ante Revenue } \\
\text { Difference }(\%)\end{array}$ \\
\hline 1 & 91.24 & 91.10 & 89.91 & 1.31 & $1.30[1.17,1.44]$ \\
\hline 2 & 90.99 & 91.04 & 89.71 & 1.47 & $1.40[0.01,1.58]$ \\
\hline 3 & 89.86 & 89.95 & 88.61 & 1.49 & $1.34[0.01,1.61]$ \\
\hline 4 & 85.50 & 85.25 & 83.59 & 1.94 & $1.33[0.02,2.02]$ \\
\hline 5 & 87.67 & 87.46 & 85.99 & 1.68 & $1.65[1.52,1.78]$ \\
\hline 6 & 88.15 & 87.50 & 86.55 & 1.09 & $1.09[0.97,1.21]$ \\
\hline 7 & 88.07 & 87.52 & 86.57 & 1.09 & $1.03[0.01,1.18]$ \\
\hline 8 & 88.04 & 88.04 & 86.65 & 1.58 & $1.57[1.30,1.80]$ \\
\hline 9 & 85.85 & 85.41 & 84.13 & 1.51 & $1.30[0.01,1.58]$ \\
\hline 10 & 85.45 & 85.15 & 83.76 & 1.64 & $1.63[1.35,1.85]$ \\
\hline 11 & 85.70 & 85.65 & 84.15 & 1.75 & $1.73[1.37,2.06]$ \\
\hline 12 & 86.05 & 85.96 & 84.60 & 1.58 & $1.55[1.14,1.84]$ \\
\hline 13 & 84.34 & 84.27 & 82.50 & 2.10 & $1.96[0.02,2.37]$ \\
\hline 14 & 86.60 & 86.21 & 84.93 & 1.49 & $1.44[1.21,1.59]$ \\
\hline 15 & 87.31 & 86.78 & 85.76 & 1.18 & $1.18[1.02,1.30]$ \\
\hline 16 & 88.58 & 88.04 & 87.15 & 1.02 & $1.01[0.88,1.11]$ \\
\hline 17 & 87.71 & 87.52 & 86.06 & 1.67 & $1.66[1.55,1.76]$ \\
\hline 18 & 88.28 & 87.81 & 86.63 & 1.35 & $1.33[1.27,1.37]$ \\
\hline 19 & 89.60 & 89.34 & 88.05 & 1.44 & $1.43[1.33,1.52]$ \\
\hline 20 & 90.34 & 90.00 & 88.86 & 1.27 & $1.27[1.16,1.37]$ \\
\hline 21 & 88.65 & 88.86 & 86.86 & 2.26 & $2.21[2.05,2.40]$ \\
\hline 22 & 90.07 & 90.02 & 88.42 & 1.78 & $1.75[1.66,1.85]$ \\
\hline 23 & 91.95 & 91.53 & 90.42 & 1.21 & $1.10[0.01,1.27]$ \\
\hline 24 & 91.72 & 91.20 & 90.25 & 1.04 & $1.04[0.97,1.11]$ \\
\hline 25 & 91.35 & 90.95 & 89.69 & 1.38 & $1.38[1.31,1.45]$ \\
\hline 26 & 91.67 & 91.15 & 90.09 & 1.17 & $1.17[1.12,1.21]$ \\
\hline 27 & 91.11 & 90.93 & 89.61 & 1.45 & $1.44[1.40,1.48]$ \\
\hline 28 & 90.65 & 90.49 & 88.95 & 1.70 & $1.69[1.59,1.79]$ \\
\hline 29 & 91.82 & 91.21 & 90.23 & 1.07 & $1.06[1.04,1.09]$ \\
\hline 30 & 93.33 & 92.18 & 91.83 & 0.39 & $0.38[0.35,0.41]$ \\
\hline 31 & 92.15 & 91.74 & 90.72 & 1.11 & $1.10[1.05,1.15]$ \\
\hline 32 & 90.78 & 90.61 & 89.03 & 1.75 & $1.74[1.70,1.78]$ \\
\hline 33 & 91.19 & 90.83 & 89.56 & 1.39 & $1.38[1.30,1.46]$ \\
\hline 34 & 90.09 & 90.21 & 88.52 & 1.88 & $1.86[1.71,2.01]$ \\
\hline 35 & 91.02 & 90.69 & 89.57 & 1.24 & $1.24[1.14,1.32]$ \\
\hline 36 & 89.49 & 89.56 & 87.84 & 1.93 & $1.92[1.71,2.11]$ \\
\hline 37 & 89.74 & 89.94 & 88.15 & 1.99 & $1.99[1.80,2.17]$ \\
\hline 38 & 90.75 & 90.76 & 89.26 & 1.66 & $1.65[1.51,1.75]$ \\
\hline 39 & 91.67 & 91.31 & 90.29 & 1.12 & $1.12[1.04,1.20]$ \\
\hline 40 & 89.39 & 89.76 & 87.52 & 2.50 & $2.49[2.41,2.55]$ \\
\hline 41 & 89.98 & 89.92 & 88.20 & 1.92 & $1.91[1.88,1.93]$ \\
\hline 42 & 90.28 & 89.97 & 88.60 & 1.52 & $1.51[1.47,1.55]$ \\
\hline
\end{tabular}

